\title{
Inhaled Pulmonary Vasodilators: Are There Indications Within the Pediatric ICU?
}

\author{
Bradley A Kuch MHA RRT-NPS FAARC, Alvin L Saville RRT, Joan Sanchez De Toledo MD, \\ and Shekhar T Venkataraman MD
}

\author{
Introduction \\ Literature Search \\ Inhaled Nitric Oxide \\ Pediatric Acute Respiratory Failure \\ Congenital and Acquired Cardiac Disease/Post-Cardiac Surgery \\ Should Inhaled Nitric Oxide Be Used Outside of the Neonatal Period? \\ Inhaled Aerosolized Pulmonary Vasodilators \\ Pharmacodynamics and Dosing \\ Epoprostenol Sodium \\ Iloprost \\ Treprostinil \\ Safety Considerations During the Delivery of Inhaled Pulmonary Vasodilators \\ Summary
}

\begin{abstract}
Inhaled nitric oxide (INO) is only FDA-cleared for neonates ( $>34$ weeks gestation) with hypoxic respiratory failure-associated pulmonary hypertension. Off-label use of INO is common in the pediatric population despite a lack of evidence regarding survival benefit, questioning whether the therapy should be considered outside the neonatal period. A lack of definitive evidence combined with increasing health-care costs has led to the use of less costly inhaled prostacyclin as an alternative to INO, presenting unique patient safety concerns. We evaluate the current evidence and patient safety considerations regarding inhaled pulmonary vasodilators in the pediatric population. Key words: pediatrics; nitric oxide; prostacyclin; pulmonary hypertension. [Respir Care 2017;62(6):678-698. (C) 2017 Daedalus Enterprises]
\end{abstract}

\section{Introduction}

All pediatric uses of inhaled pulmonary vasoactive agents are off-label and controversial regarding their safety and efficacy. Commonly used agents include inhaled nitric oxide (INO), aerosolized epoprostenol sodium, iloprost, and treprostinil. Evidence supporting inhalational administra-

\footnotetext{
Mr Kuch, Mr Saville, and Dr Venkataraman are affiliated with the Department of Respiratory Care Services, and Mr Kuch is also affiliated with the Transport Team, Children's Hospital of Pittsburgh of University of Pittsburgh Medical Center, Pittsburgh, Pennsylvania. Drs Sanchez De Toledo and Venkataraman are affiliated with the Departments of Critical Care Medicine and Pediatrics, University of Pittsburgh School of Medicine, Pittsburgh, Pennsylvania.
}

The authors have disclosed no conflicts of interest
Mr Kuch presented a version of this work at the 55th RESPIRATORY CARE Journal Conference, "Pediatric Respiratory Care," held June 10-11, 2016 , in St Petersburg, Florida.

Correspondence: Bradley A Kuch MHA RRT-NPS FAARC, Children's Hospital of Pittsburgh of UPMC, 4401 Penn Avenue, Suite 5465, Pittsburgh, Pennsylvania 15224. E-mail: bradley.kuch@chp.edu.

DOI: $10.4187 /$ respcare.05360 


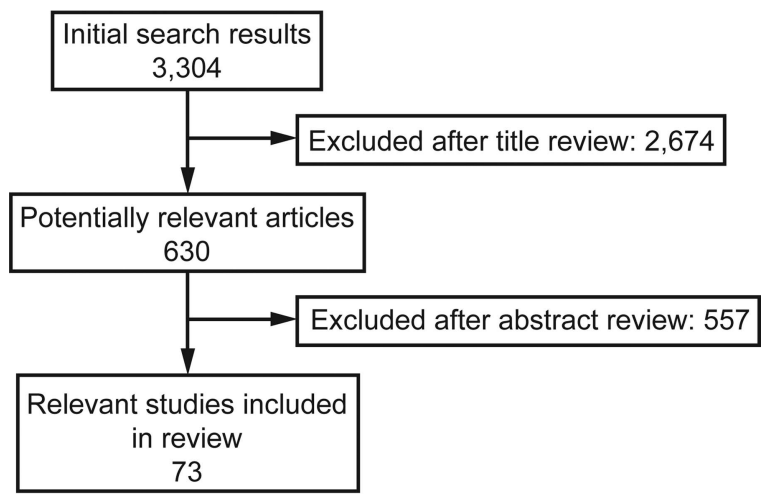

Fig. 1. Literature review flow chart. Search parameters were English language, human studies, children (1 month to $18 \mathrm{y}$ of age), and publication date between January 1, 1990, and June 1, 2016. Search terms were: inhaled pulmonary vasodilators, inhaled nitric oxide, inhaled prostacyclin, inhaled iloprost, inhaled epoprostenol, and inhaled treprostinil.

tion of these medications in the pediatric population is limited and inconclusive. The health-care transition from volume-based to value-based reimbursement models has increased administrative scrutiny concerning health-care cost and outcome. A lack of supportive evidence, direct delivery costs, and patient safety concerns continue to fuel the debate over the following questions. (1) Should inhaled pulmonary vasodilators be used outside the neonatal period? (2) What duration of INO therapy should be used before considering an alternative pulmonary vasodilator? (3) Is INO associated with improved survival outcomes in children? (4) Is INO useful outside of its indicated use? (5) What other pulmonary vasodilators can be considered in the pediatric population? (6) What complications are associated with inhaled pulmonary vasodilator administration?

\section{Literature Search}

To identify potentially relevant literature addressing the above-mentioned questions, a PubMed (MEDLINE) search was conducted using the following search terms and criteria. Each search term was limited to English language, human studies, and children (1 month to $18 \mathrm{y}$ of age): "inhaled pulmonary vasodilators,"; "inhaled nitric oxide,"; "inhaled prostacyclin,"; "inhaled iloprost,"; "inhaled epoprostenol,"; and "inhaled treprostinil," (Fig. 1). The selected time frame included papers published between January 1, 1990, and June 1, 2016. References and abstracts were retrieved and reviewed by the authors for additional analysis.

Through inspection of reference titles, references with no relevance to this review's questions were eliminated. The remaining references' abstracts were reviewed for relevance and eliminated as deemed appropriate. The remain- ing references' cross-references were evaluated to identify additional literature to be added as they relate to the focus of the review questions. Subsequently, 73 relevant articles were included in this review.

\section{Inhaled Nitric Oxide}

Nitric oxide is a potent pulmonary vasodilator synthesized in the vascular endothelium. Generated in vivo from L-arginine in the presence of nitric oxide synthase, NO activates soluble guanylate cyclase, increasing intracellular cyclic guanosine monophosphate, inhibiting the entry of calcium into the cell. ${ }^{1}$ The second pathway is activation of $\mathrm{K}^{+}$channels, leading to hyperpolarization and vascular dilatation. The final component is stimulation of cyclic guanosine monophosphate-dependent protein kinase, which activates myosin light chain phosphatase, leading to dephosphorylation and further smooth muscle relaxation. ${ }^{1}$ When delivered via the respiratory tract, the principal effect occurs in adequately ventilated areas of the lung, producing localized short-term pulmonary vasodilatation with little systemic effect. Nitric oxide has also been found to down-regulate leukocyte response, decrease platelet aggregation, facilitate neurotransmission, reduce apoptosis, augment bronchodilation, and attenuate inflammatory responses from cellular injury after cellular ischemia and/or tissue reperfusion. ${ }^{1}$

In 1999, the FDA cleared inhaled nitric oxide for neonatal patients ( $>34$ weeks gestation) with hypoxic respiratory failure associated with clinical or echocardiographic evidence of pulmonary hypertension. ${ }^{2}$ The clearance and commercial availability of a reliable delivery system facilitated INO therapy's crossover into other theoretical clinical applications. Currently, the agent's effectiveness and relatively safe therapeutic profile makes INO a common therapeutic approach for treatment of neonatal acute hypoxic respiratory failure with and without elevated pulmonary pressures, isolated pulmonary hypertension, cardiac and lung transplantation, severe ARDS, and pediatric acute hypoxemic respiratory failure.

Increasing health-care costs and decreasing reimbursement have led to administrative scrutiny regarding the use of INO, as direct-delivery costs of INO administration impact operating margins of all health-care organizations. It has been reported that direct cost of INO delivery was $\$ 100 / \mathrm{h}$ for an annual cost of $\$ 1.8$ million institution-wide in a single pediatric tertiary care center. ${ }^{3}$ These projections are conservative, since other cost estimates approach $\$ 125 / \mathrm{h}$ with large academic tertiary pediatric centers assuming \$1-4 million annually in INO cost. ${ }^{4}$ Moreover, the projected United States health-care inflation rate is estimated at $2.6 \%$ for 2016, adding additional annual fiscal outlays (Bureau of Labor Statistics, http://data.bls.gov/timeseries/ CUUR0000SAM?output_view=pct_12mths, Accessed 


\section{InHaled Pulmonary Vasodilators IN THE PICU}

March 9, 2016). These considerations have renewed the effort to reduce practice variation, improve quality, and more efficiently utilize the expensive therapy of INO. It has been demonstrated that implementation of standardized INO initiation and weaning guidelines/protocols are effective in decreasing practice variation and direct INO cost without impacting mortality. ${ }^{3}$ It is difficult to support the use of clinical guidelines regarding INO at this time, because no conclusive evidence exists supporting survival benefit associated with INO delivery in the pediatric population.

\section{Pediatric Acute Respiratory Failure}

INO for treatment of pediatric acute respiratory failure remains debatable, with outcome benefit from varying etiologies being unfounded. INO is thought to reverse ventilation/perfusion mismatch by selectively mediating pulmonary vasomotor tone in well-ventilated regions of the lung, reducing pulmonary vascular resistance, pulmonary hypertension, and right heart work load. ${ }^{5}$ Acute clinical response to INO has been reported in small case series, demonstrating immediate improvement in oxygenation at low concentrations (Table 1). ${ }^{6-8} \mathrm{Abman}^{\text {et }} \mathrm{al}^{6}$ described the use of INO in 17 children with severe hypoxic respiratory failure from non-homogeneous etiologies. Diagnosis included ARDS $(n=10)$, bronchopulmonary dysplasia $(n=6)$, and acute pneumonitis $(n=1) .{ }^{6}$ Compared were $\mathrm{P}_{\mathrm{aO}}$ and hemodynamics before and during INO therapy, with measurements collected $30 \mathrm{~min}$ after the initiation of therapy. ${ }^{6}$ They demonstrated immediate improvement in oxygenation (mean $\mathrm{P}_{\mathrm{aO}_{2}}=58 \pm 13 \mathrm{~mm} \mathrm{Hg}$ vs $86 \pm 25 \mathrm{~mm} \mathrm{Hg}, P<.01)$, lower mean pulmonary artery pressure $(42 \pm 6 \mathrm{~mm} \mathrm{Hg}$ vs $31 \pm 6 \mathrm{~mm} \mathrm{Hg}, P<.01)$, decreased intrapulmonary shunt $(39 \pm 7 \%$ vs $32 \pm 7 \%$, $P<.01)$, and an increase in cardiac index by $14 \%(P<.01){ }^{6}$ Abman et $\mathrm{al}^{6}$ concluded that INO acutely improved oxygenation and decreased pulmonary vascular resistance without adverse hemodynamic consequences in children with severe acute hypoxemic respiratory failure. The study was not powered to identify mortality benefit. Okamoto et $\mathrm{al}^{7}$ reported similar findings in small series of 7 children with pediatric ARDS. The American-European Consensus Conference definition of ARDS was used to identify potential subjects. ${ }^{12}$ Etiologies of ARDS included both direct and indirect origins. The study protocol incorporated 2 phases. Phase 1 included baseline ( $1 \mathrm{~h}$ of steady-state pressure control ventilation) and post-INO initiation (30 min after start of nitric oxide inhalation) measurements. ${ }^{7}$ Phase 2 evaluated INO dose response on the following day on the same ventilator setting as phase 1 , including the discontinuation of the therapy and evaluation of respiratory and hemodynamic measures at INO concentrations of 0.13 , $0.25,0.5,1,2,4,8$, and 16 parts ppm. ${ }^{7}$ Results demon- strated that $16 \mathrm{ppm}$ of INO produced improvement in $\mathrm{P}_{\mathrm{aO}_{2}} / \mathrm{F}_{\mathrm{IO}_{2}}(68 \pm 10$ vs $136 \pm 37, P<.02)$ and $\mathrm{S}_{\mathrm{pO}_{2}}(93 \pm 1 \%$ vs $99 \pm 1 \%, P<.05$ ), with a significant correlation between the INO-induced $\mathrm{P}_{\mathrm{aO}} / \mathrm{F}_{\mathrm{IO}_{2}}$ increase from baseline $\mathrm{P}_{\mathrm{aO}_{2}} / \mathrm{F}_{\mathrm{IO}_{2}}$ measures $(\mathrm{r}=0.93, P<.01) .^{7}$ The alveolararterial oxygen difference also decreased from $594 \pm 11$ to $529 \pm 38 \mathrm{~mm} \mathrm{Hg}(P<.02) .{ }^{7}$ Hemodynamics increased slightly during nitric oxide inhalation; increases included systolic arterial blood pressure $(95 \pm 10 \mathrm{~mm} \mathrm{Hg}$ vs $100 \pm 10 \mathrm{~mm} \mathrm{Hg}, P<.05$ ), Mean arterial blood pressure $(67 \pm 7 \mathrm{~mm} \mathrm{Hg}$ vs $72 \pm 8 \mathrm{~mm} \mathrm{Hg}, P<.05)$, and diastolic arterial blood pressure $(52 \pm 6 \mathrm{~mm} \mathrm{Hg}$ vs $56 \pm 7 \mathrm{~mm} \mathrm{Hg}$, $P<.05)$, respectively. ${ }^{7}$ Dose-response tests have shown the optimal concentration of INO to be $\leq 4 \mathrm{ppm}$, with improvements observed at concentrations as low as $\leq 1$ ppm. ${ }^{7}$ The group concluded that INO frequently improved oxygenation in children with ARDS with improvements observed at concentrations $\leq 1 \mathrm{ppm}$, a dose that decreases the risk of toxic reactions. ${ }^{7}$

Sheridan et $\mathrm{al}^{8}$ sought to assess the effect of INO on intrapulmonary shunt in 11 children with ARDS secondary to inhalational and burn injury. Intrapulmonary shunt was measured by $\mathrm{P}_{\mathrm{aO}_{2}} / \mathrm{F}_{\mathrm{IO}_{2}}$ immediately before and $1 \mathrm{~h}$ after INO initiation. The mean age of the cohort was $8.3 \pm 4.8 \mathrm{y}$, with a mean burn size of $64 \pm 22 \%$ of total body surface area and a mean Murray lung score of $3.1 \pm 0.5$ at study entry. Initial concentration of nitric oxide was $5.8 \pm 1.9 \mathrm{ppm}$, and maintenance was $6.7 \pm 2.4 \mathrm{ppm}$. Findings from this small study demonstrated that low-dose INO improved $\mathrm{P}_{\mathrm{aO}_{2}} / \mathrm{F}_{\mathrm{IO}_{2}}$ from baseline $(94.9 \pm 50 \mathrm{~mm} \mathrm{Hg}$ vs $190 \pm 74 \mathrm{~mm} \mathrm{Hg}, P$ value not provided). $\mathrm{P}_{\mathrm{aO}_{2}} / \mathrm{F}_{\mathrm{IO}_{2}}$ increased by an average of $162 \pm 214 \% .{ }^{8}$ Non-survivors had significantly less of a response when compared with survivors $(7.3 \pm 6.4 \%$ vs $213 \pm 226 \%, P=.03)$. The authors concluded that INO can be safely administered to treat ARDS in children with burns and appears to aid ventilator management. In addition to their conclusions, they hypothesize that immediate improvement in oxygenation with the delivery of nitric oxide may be associated with survival. ${ }^{8}$

Larger studies demonstrated similar findings in pediatric ARDS. Fioretto et $\mathrm{al}^{9}$ conducted a prospective historically controlled observational study evaluating the acute and sustained effect of INO compared with conventional therapy. Pediatric ARDS was defined according to the American European Consensus Conferences definition published in $1994 .{ }^{9}$ The primary aim of this study was to evaluate the early administration of INO as it relates to improvement in oxygenation measures and reduction in ventilator parameters, ICU stay, and mortality. Oxygenation assessment included $\mathrm{P}_{\mathrm{aO}} / \mathrm{F}_{\mathrm{IO}_{2}}$ and oxygenation index (OI) at baseline, $30 \mathrm{~min}$, and $4 \mathrm{~h}$ in the INO group. ${ }^{9}$ Inhaled nitric oxide therapy was initiated at a median of $1.5 \mathrm{~h}$ (range 1-96 h) following the diagnosis of ARDS. ${ }^{9}$ 


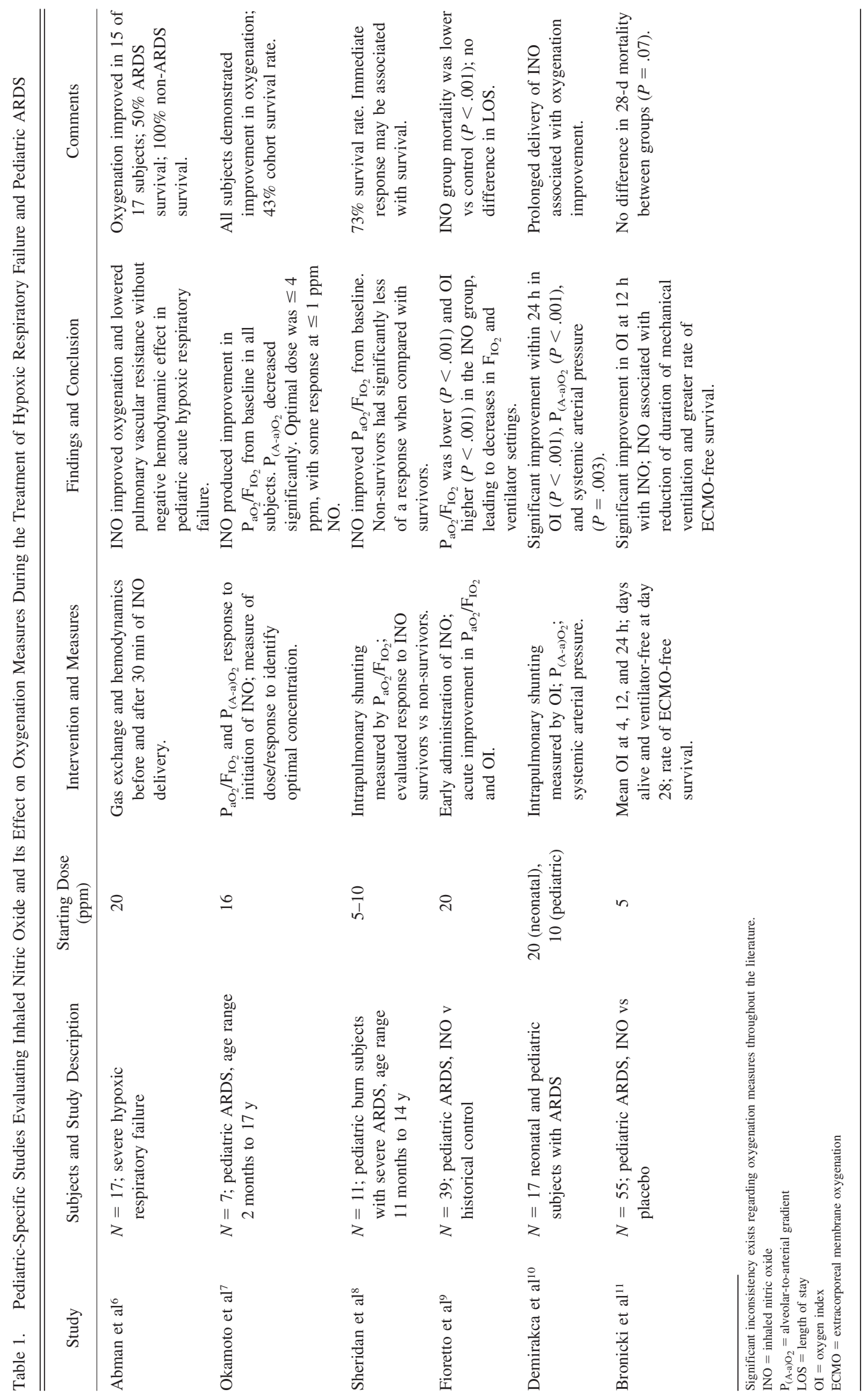




\section{InHaled Pulmonary Vasodilators IN THE PICU}

Administration of INO improved oxygenation, as measured by both the $\mathrm{P}_{\mathrm{aO}_{2}} / \mathrm{F}_{\mathrm{IO}_{2}}$ and $\mathrm{OI}$ at $30 \mathrm{~min}$ and $4 \mathrm{~h}$ after initiation. ${ }^{9}$ Comparative analysis revealed that $\mathrm{F}_{\mathrm{IO}_{2}}$ and peak inspiratory pressure could be quickly reduced. ${ }^{9}$ The group also found a lower mortality rate in the INO group $(16.5 \%$ vs $47.6 \%, P<.001)$, which is particularly interesting, given the fact that the INO group had significantly lower $\mathrm{P}_{\mathrm{aO}} / \mathrm{F}_{\mathrm{IO}_{2}}$ values and higher OI that may indicate a greater severity of lung injury. ${ }^{9}$ No difference in ICU stay or duration of mechanical ventilation was found. ${ }^{9}$ Fioretto et $\mathrm{al}^{9}$ concluded that early initiation of INO resulted in acute and sustained improvement in oxygenation and a reduction in ventilator settings, which may contribute to a reduction in mortality rate in pediatric ARDS. The study had several limitations. The statistical power and overall level of this evidence is limited as a result of its nonrandomized design and small number of subjects. Furthermore, the historical controls and co-interventional variance over the 4-y period may have contributed to the outcome. Case in point: The INO group had a higher mean airway pressure, PEEP, and $\mathrm{P}_{\mathrm{aCO}}$ levels at the time of enrollment, which leads to the question of whether the outcome benefit was associated with INO or the lungprotective ventilation strategy.

More recently, Bronicki et al ${ }^{11}$ conducted a multi-center randomized controlled blinded trial comparing low-dose (5-ppm) inhaled nitric oxide with a placebo (nitrogen) in children with ARDS. Fifty-five children were randomized from 5 centers between 2003 and 2005.12 Study subjects remained on the assigned study drug until death, separation from mechanical ventilation, or day 28 after the initiation of therapy. ${ }^{11}$ Oxygenation was measured using the OI, with assessment made at 4,12 , and $24 \mathrm{~h}$ following study initiation. ${ }^{11}$ Outcome measures included days alive and ventilator-free at day 28 , survival, and rate of extracorporeal membrane oxygenation (ECMO)-free survival. ${ }^{11}$ The group reported a trend in OI at hour 4, which became statistically significant at hour 12 . They found no difference between groups at the 24-h time point. ${ }^{11}$ The INO group had a significantly greater number of days alive and ventilator-free $(14.2 \pm 8.1 \mathrm{~d}$ vs $9.1 \pm 9.5 \mathrm{~d}, P=.05)$ and rate of ECMO-free survival $(92 \%$ vs $52 \%, P<.01)$. Bronicki et al $^{11}$ concluded that low-dose INO was associated with a reduction in duration of mechanical ventilation and a greater rate of ECMO-free survival. This study was the first to evaluate the outcome of pediatric ARDS without crossover, identifying the impact of INO on outcome. The mechanisms responsible for improved outcomes of this study are unknown, and, given the short duration of oxygenation improvement, it does not appear to be related to a sustained enhanced oxygenation. ${ }^{11}$ A potential mechanism for which INO may improve outcome in pediatric ARDS may be related to its modulation of coagulation and inflammation, since both play a prominent role in patho- genesis of the disease. ${ }^{13-18}$ Limiting the risk of thromboocclusion while reducing inflammatory-mediated alveolar damage, in theory, should improve outcome. However, this benefit has not been demonstrated as it relates to mortality outcomes. There were several limitations with this study. The sample size was small for a study that included 9 North American centers. Also, the subjects were enrolled over 10 y ago, a time when ventilation strategies were inconsistent and evolving. The authors also note that "guidelines on the management of mechanical ventilation were established by the investigators; however, the study lacked an explicit protocol." 11 The absence of a definitive mechanical ventilation protocol creates a potential for practice variation, which could potentially lead to an underestimate of the treatment benefit of INO.

The most recent meta-analysis from the Cochrane Collaboration conducted by Afshari et al ${ }^{19}$ evaluated 14 randomized controlled trials that included 1,303 subjects. All included studies compared INO with no intervention or placebo controls. The subject population included both children and adults with ARDS or acute lung injury, and the primary outcome measure was allcause mortality. Additional outcomes included improvement of oxygenation, duration of mechanical ventilation, ventilator-free days, and ICU and hospital stay. ${ }^{19}$ The authors reported a statistically significant improvement in $\mathrm{P}_{\mathrm{aO}_{2}} / \mathrm{F}_{\mathrm{IO}_{2}}$ and $\mathrm{OI}$ in the first $24 \mathrm{~h}$ of administration. ${ }^{19}$ However, limited data demonstrated an insignificant effect of INO on duration of mechanical ventilation, ventilator-free days, and stay in the ICU and hospital. ${ }^{19}$ The authors found no mortality difference between groups with little variation in the pooled studies, as indicated by an $\mathrm{I}^{2}$ value of $0(40.2 \%$ vs $38.6 \%$, relative risk $\left.1.06,95 \% \mathrm{CI} 0.93-1.22, \mathrm{I}^{2}=0\right) .{ }^{19}$ There was an apparent increased risk of renal impairment among the adult population that was not seen in children. ${ }^{19}$ From these data, it was concluded that INO results in a transient improvement in oxygenation; however, INO cannot be recommended for patients with acute hypoxic respiratory failure. ${ }^{19}$ These findings validate the finding of the prior Cochrane Collaboration review conducted by Sokol et al, ${ }^{20}$ who concluded that INO transiently improved oxygenation but did not positively affect mortality. Both of these meta-analyses had limitations, which included the use of data sets that had both adult and pediatric populations. It is well understood that the pathology and response to ARDS differ greatly between adults and children. ${ }^{21,22}$ Case in point: The most common etiology for ARDS in adults is sepsis (indirect), whereas in children, it is pneumonia (direct). ${ }^{23,24}$ Furthermore, children's comorbidities differ greatly from those of the adult population. Limitations such as these indicate the need for more comprehensive 


\section{InHaled Pulmonary Vasodilators IN THE PICU}

studies evaluating the effect of INO on outcome on more homogeneous data sets with well-defined secondary outcomes.

Recently, Gupta et al ${ }^{25}$ conducted a retrospective propensity score-matched study using linked data from 2 national registries evaluating the effect of inhaled nitric oxide on outcome in children with acute lung injury. Linked data were from the Virtual Pediatric System LLC database and the Pediatric Health Information System focusing on the most recent 6 y (2009-2014). Initial analysis included 20,106 children $(<18$ y of age $)$ from 9 hospitals who were mechanically ventilated for acute lung injury. Propensity score development identified 1,042 subjects matched oneto-one and separated into 2 groups: Group $1(n=521)$ received INO for $>24 \mathrm{~h}$, and Group $2(n=521)$ did not receive INO during their hospital course. ${ }^{25}$ Variables were included from the following categories: baseline demographics, ICU admission, clinical data, procedural, diagnostic, and outcome measures. ${ }^{25}$ The group evaluated both unadjusted (before matching) and propensity-matched outcomes. Unadjusted outcomes revealed that children receiving INO were younger, with more comorbidities, greater severity of illness, increased incidence of cardiopulmonary resuscitation, greater resource utilization, and higher mortality rate. ${ }^{25}$ Propensity score matching demonstrated no difference in mortality. However, other outcomes, including ventilator-free days, duration of mechanical ventilation, ICU and hospital stay, and hospital costs, were significantly worse in the group treated with nitric oxide. ${ }^{25}$ Gupta et al ${ }^{25}$ concluded that INO is not associated with improved mortality rates; rather, it is associated with increased hospital utilization and cost. The findings of this study are significant because the study utilized the most up-to-date data available, reflecting current treatment strategies, including lung-protective ventilation, prone positioning, use of ECMO, and renal replacement therapy. In addition, the observational comparative effectiveness study design using propensity matching represents real-life practice without the limitation of study protocols. ${ }^{25}$ The design also removes the potential for biased patient selection regarding treatment while addressing effectiveness and outcome. However, the study had several potential limitations. First, propensity matching only occurs on observed variables, making it possible that unmeasured factor(s) may have had an effect on outcome. Second, the data were obtained from multi-center registries, which calls into question data integrity, compliance, and validation. Furthermore, there is the potential for coding errors within large data sets. Finally, the study lacked information on key variables, such as oxygenation measures, acute lung injury etiologies, and mechanical ventilation data.

\section{Congenital and Acquired Cardiac Disease/Post-Cardiac Surgery}

Pulmonary vascular endothelial dysfunction resulting in pulmonary hypertension has been a long-accepted complication following the repair of congenital cardiac lesions, often exacerbated by cardiopulmonary bypass. ${ }^{26,27}$ One of the first known clinical studies of INO to treat postoperative pulmonary hypertension was conducted by Wessel et al, ${ }^{28}$ who investigated the etiology of pulmonary vascular endothelial dysfunction before and after cardiac lesion repair requiring cardiopulmonary bypass. They characterized pulmonary vascular dysfunction via a decreased response to acetylcholine postbypass. ${ }^{28}$ It was found that the vascular dysfunction was associated with an increased response to INO when compared with pre-bypass measures. ${ }^{28}$ The group also reported a 3-fold increase in plasma level of cyclic guanosine monophosphate during delivery of INO. ${ }^{28}$ The findings of this study led to additional small trials evaluating the administration of INO in treating refractory pulmonary hypertension that suggested a potentially lifesaving role of INO. ${ }^{29,30}$

Early small studies evaluated the effect of INO for the treatment of pulmonary hypertension for surgical repair of congenital heart disease (Table 2). Russell et al ${ }^{32}$ used a randomized controlled double-blind study to compare 40 children undergoing cardiopulmonary bypass for repair of congenital cardiac lesions. Pulmonary hypertension was defined as a mean pulmonary artery pressure $>50 \%$ of the mean systemic arterial pressure. ${ }^{32}$ Thirteen subjects $(36 \%)$ were separated from cardiopulmonary bypass with pulmonary hypertension. ${ }^{32}$ All subjects with pulmonary hypertension responded to INO with an average reduction of $19 \%$ in mean pulmonary artery pressure at $20 \mathrm{~min} .{ }^{32}$ No difference between groups was found when comparing mean systemic arterial pressure, heart rate, and arterial pressure following initiation of INO. ${ }^{32}$ The authors concluded that INO selectively decreases mean pulmonary artery pressure in children with pulmonary hypertension following cardiopulmonary bypass surgery. ${ }^{32}$ Limitations of this study have created some questions regarding the author's findings. Pulmonary vascular resistance was not directly measured, which leads to the question whether the decrease in mean pulmonary artery pressure was an effect of INO or a decreased cardiac output. The fact that there was no documented decrease in mean systemic arterial pressure leads to the conclusion that the decrease in pulmonary pressure probably occurred from a decrease in pulmonary vascular resistance. However, a decrease in cardiac output cannot be ruled out. Furthermore, the small $(19 \%)$ reduction in mean pulmonary artery pressure witnessed in this study may suggest that hyperven- 

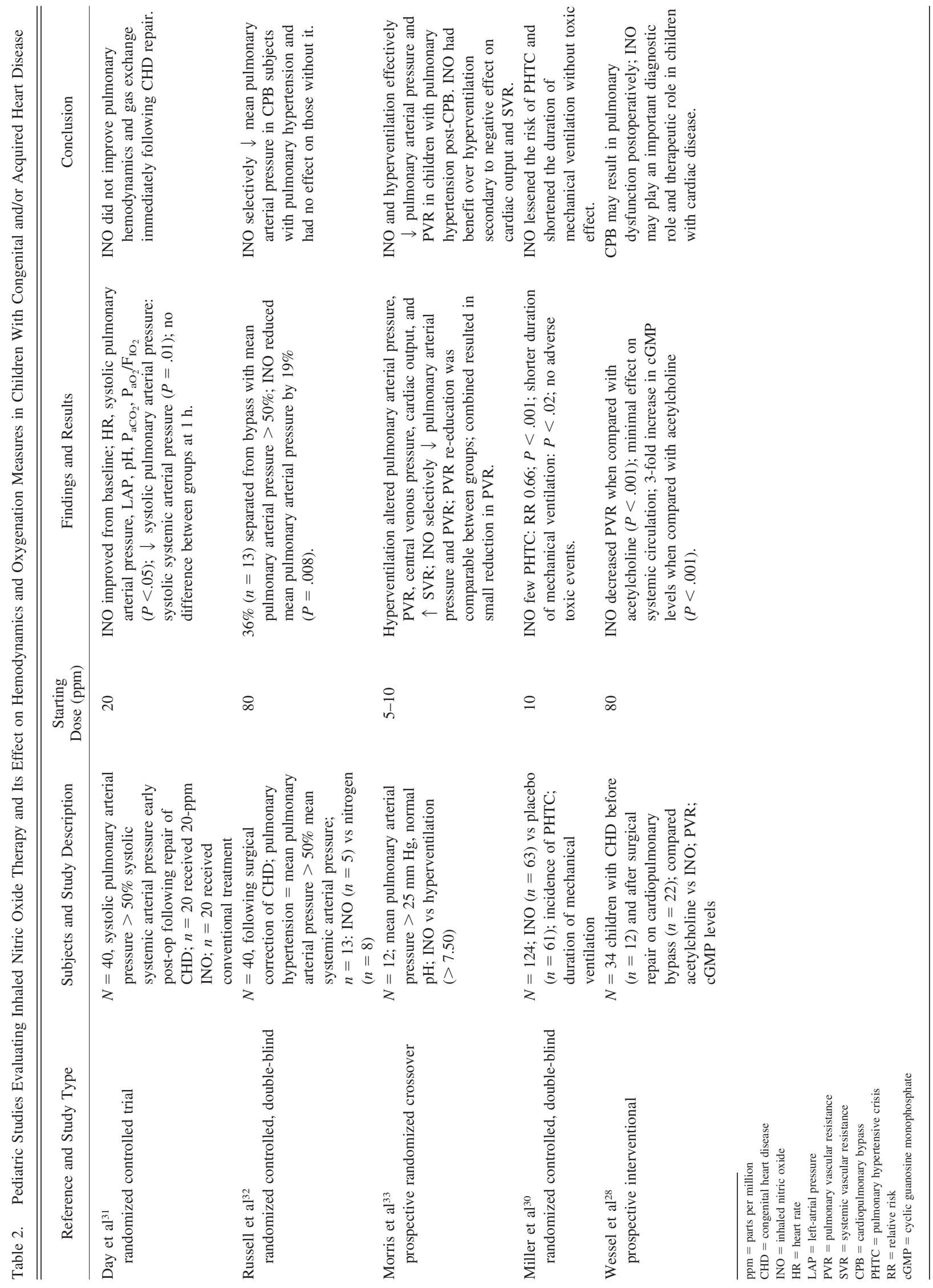


\section{InHaled Pulmonary Vasodilators IN THE PICU}

tilation and $100 \%$ oxygen administration could have the same effect. ${ }^{32}$ That being said, hyperventilation and $100 \%$ oxygen delivery are not without risk. This practice may decrease cardiac output via increased mean airway pressure and systemic vascular resistance while increasing the risk of hyperoxic lung injury. ${ }^{33,34}$

The effect of conventional hyperventilation compared with INO has been evaluated in a prospective randomized crossover study in children $(n=12)$ with pulmonary hypertension (pulmonary artery pressure $>25 \mathrm{~mm} \mathrm{Hg}$ ) following repair of congenital heart disease. ${ }^{33}$ Measurements included cardiac output derived from hemodynamic parameters in subjects assigned to either INO or hyperventilation. Therapeutic hyperventilation was achieved without change in mean airway pressure. ${ }^{33}$ Morris et $\mathrm{al}^{33}$ reported that hyperventilation was as effective in decreasing pulmonary artery pressure and pulmonary vascular resistance as INO. However, hyperventilation resulted in a decrease in cardiac output and an increase in systemic vascular resistance. ${ }^{33}$ They concluded that INO and hyperventilation are both effective at lowering pulmonary artery pressure and pulmonary vascular resistance; INO selective action on the pulmonary circulation offers advantages over hyperventilation. ${ }^{33}$ The study, albeit small, suggests that the use of INO in children with pulmonary hypertension undergoing cardiopulmonary bypass for repair of congenital heart disease may aid in the reduction of right heart work load.

Two randomized control trials have addressed the effectiveness of INO for the treatment of postoperative pulmonary hypertension following repair of congenital heart disease. Day et $\mathrm{al}^{31}$ randomized children with pulmonary hypertension to receive either $20 \mathrm{ppm}$ INO $(n=20)$ or conventional therapy $(n=20)$, evaluating the incidence of pulmonary hypertensive crisis per group. Pulmonary hypertension was defined as a systolic pulmonary pressure $\geq 50 \%$ of systemic arterial pressure, reported as the ratio of systolic pulmonary to systolic systemic arterial pressure. ${ }^{31}$ Results demonstrated a small but significant decrease in systolic pulmonary arterial pressure/systolic systemic arterial pressure 1-hour after INO initiation in the study group $(P=.01) .{ }^{31}$ No difference between subject groups was observed at baseline or $1 \mathrm{~h}(P=.066) .{ }^{31}$ Three subjects in the INO group and 4 in the control group experienced life-threating pulmonary hypertensive crisis. ${ }^{31}$ A power analysis revealed that $>2,000$ subjects would be needed to determine if INO decreases the incidence of pulmonary hypertensive crisis. ${ }^{31}$ It was concluded that INO "did not substantially improve hemodynamics and gas exchange" immediately following congenital cardiac surgery and "failed to decrease the incidence of pulmonary hypertensive crisis." 31 These data suggest limited value of INO in this patient population. Weighing the quality of this evidence comes with caution, since the authors point out that no treatment protocols were followed during the study period, creating significant risk of bias regarding subject selection and use of pharmacologic adjuncts. $^{31}$

The second study is the largest randomized placebo controlled trial investigating the use of INO to limit pulmonary hypertensive crisis following congenital cardiac surgery. This study compared 124 infants randomly assigned to either low-dose $(10 \mathrm{ppm})$ INO $(n=61)$ or a placebo $(n=63)$, evaluating the number of pulmonary hypertensive crises, time receiving the study gas, and ICU stay. ${ }^{30}$ Subjects who received INO had 30\% fewer pulmonary hypertensive crises and had a shorter median time to extubation readiness. ${ }^{30}$ The study was underpowered to estimate mortality outcome benefit, which is a common problem in developing randomized controlled trials in this specific patient population.

Limitations of these studies are well outlined in a Cochrane review conducted by Bizzarro et al, ${ }^{35}$ who concluded that no difference was found with the use of INO in mortality, number of pulmonary hypertensive crises, change in mean pulmonary artery pressure, heart rate, or $\mathrm{P}_{\mathrm{aO}_{2}} / \mathrm{F}_{\mathrm{IO}_{2}}$. The review only included 4 randomized trials, which included 210 participants. ${ }^{35}$ They noted a significant lack of measured clinical outcomes that included long-term mortality, stay, and neurodevelopmental outcomes. ${ }^{35}$ More importantly, the authors stated, "it was difficult to draw valid conclusions given concerns regarding methodological quality, sample size, and heterogeneity." 35

Given these data and their limitations, it is difficult to draw any conclusion regarding INO therapy following repair of congenital heart disease. Use of INO in children with congenital heart disease appears to decrease pulmonary pressure during diagnostic evaluation, as well as preand post-surgical repair. Reduction of pulmonary vascular resistance appears to affect oxygenation in a small number of well-designed ICU-based studies. However, these studies are not powered to show mortality benefit. Compounding the issue of mortality as an outcome measure is that underlying anatomic anomalies may limit the effectiveness of INO. Furthermore, congenital heart disease is often complicated by accompanying congenital anomalies that may result in morbidity and mortality unrelated to lung vasoactivity. For these reasons, additional study is needed to better understand the effect of INO on mortality. At this time, it is difficult to draw any conclusions surrounding its role as a therapy to decrease pulmonary vascular resistance in children with either acquired or congenital heart disease, and it should be considered as an adjunctive rescue therapy in the presence of documented pulmonary hypertension. 


\section{InHaled Pulmonary Vasodilators IN THE PICU}

\section{Should Inhaled Nitric Oxide Be Used Outside of the Neonatal Period?}

Inhaled nitric oxide is only cleared for neonatal patients (>34 weeks gestation) with hypoxic respiratory failure associated with clinical or echocardiographic evidence of pulmonary hypertension, and all pediatric applications remain off-label. Despite this, its application continues to grow in the pediatric ICU. Definitive conclusions regarding the use and benefit of the therapy outside the neonatal period remain controversial. Inhaled NO seems to acutely improve oxygenation in children with acute hypoxemic respiratory failure in the first $24-96 \mathrm{~h}$ of therapy; however, there is no evidence demonstrating outcome benefit associated with its use. ${ }^{6-8,9,11}$ The lack of evidence regarding mortality should be considered, because therapies aimed at modifying lung disease have little effect outcome, since systemic inflammation, multi-organ dysfunction, and immunosuppression are significant contributors to the pathogenesis of pediatric ARDS and its outcome.5,36-38 Moreover, INO has been associated with greater ECMO-free survival and may decrease the need for extracorporeal support in children.

Significant disagreement exists regarding the benefit of INO administration during ECMO in the pediatric population. Recent evidence from a large post hoc analysis of data from an administrative database calls into question the benefit of the therapy among pediatric patients receiving extracorporeal life support for respiratory or cardiac etiologies. Tadphale et al ${ }^{39}$ compared subjects receiving INO during ECMO (INO group) with ECMO subjects not receiving the therapy at any point during their hospital stay (no INO group). They reported no survival benefit associated with the use of INO during ECMO support. Rather, the group demonstrated increased morbidity, longer duration of mechanical ventilation, longer length of hospital stay, and higher hospital costs. These results should be reviewed with caution, because bias may exist regarding case mix between groups, lack of information regarding type of ECMO support (ie, venoarterial or venovenous), and the inability to control for severity of illness. For this reason, the authors suggest that their findings be interpreted as exploratory. ${ }^{39}$ That being said, these data do seem to suggest that INO therapy during ECMO may not affect outcome in both severe respiratory and cardiac failure.

The use of goal-directed treatment guidelines has been advocated to decrease cost associated with administration of inhaled nitric oxide. Although single-center reports suggest that protocols may decrease direct INO delivery costs, it is difficult to support their use at this time, because currently no evidence exists supporting a survival benefit in the pediatric population. ${ }^{3}$ More study is needed regarding the incorporation of INO into goal-directed protocols; using evidence-based lung-protective strategies optimizing mechanical ventilation and reversing hypoxemia until further critical care intervention can occur may benefit patient outcomes. Although the most recent evidence suggest no mortality benefit associated with the use of INO, it does not address the benefit associated with the use of goal-directed therapies, which include inclusion criterion, definition of responders, and weaning strategies for the non-responder population. Long-term administration of INO and its effect on inflammatory modulation during the acute phase of acute lung injury/pediatric ARDS cannot be ruled out. ${ }^{10,40}$ Additional study is needed to discern the benefit of INO as it relates to its anti-inflammatory effect on long-term measures, such as pulmonary function, home oxygen requirements, and quality of life measures. Until more definitive evidence is reported, INO should only be considered as a recue therapy in severe acute respiratory failure or documented right-sided heart dysfunction and cannot be recommended for the routine treatment of acute hypoxic respiratory failure in children.

\section{Inhaled Aerosolized Pulmonary Vasodilators}

Some authors have proposed the use of more cost-effective inhaled pulmonary vasodilators to defray growing INO costs. Literature has suggested that aerosolized epoprostenol, milrone, iloprost, and treprostinil may be effective alternatives to INO for acute and/or chronic pulmonary hypertension. Inhaled prostacyclin has been proven to act as a selective pulmonary vasodilator in adult ARDS and following repair of congenital heart disease (Table 3). ${ }^{47-51}$ Evidence suggests these agents may improve oxygenation and right-ventricle afterload and are equally effective as a rescue therapy in infants and children with pulmonary hypertension as INO; nevertheless, significant safety concerns exist regarding the lack of backup delivery systems and delivery alarms and negative effects on mechanical ventilators. Aerosolized pulmonary vasodilators have the theoretical potential to improve oxygenation through decreasing ventilation-perfusion mismatching, lowering pulmonary vascular resistance, and decreasing right-ventricle afterload and may affect the outcome of children with pulmonary hypertension associated with ARDS/acute lung injury and congenital heart disease. ${ }^{41,42}$ Most evidence regarding aerosolized selective pulmonary vasodilators focuses on the use of epoprostenol, which has been shown have similar efficacy, lower potential for systemic adverse effects, and lower cost than nitric oxide. ${ }^{41,42,52}$ These attributes have propagated the use of inhaled prostacyclin despite the lack of high-level clinical evidence evaluating mortality as a primary outcome.

The topic of aerosolized pulmonary vasodilators remains controversial; thus, examining the topic requires an understanding of the each agent's pharmacodynamics, dosing, 


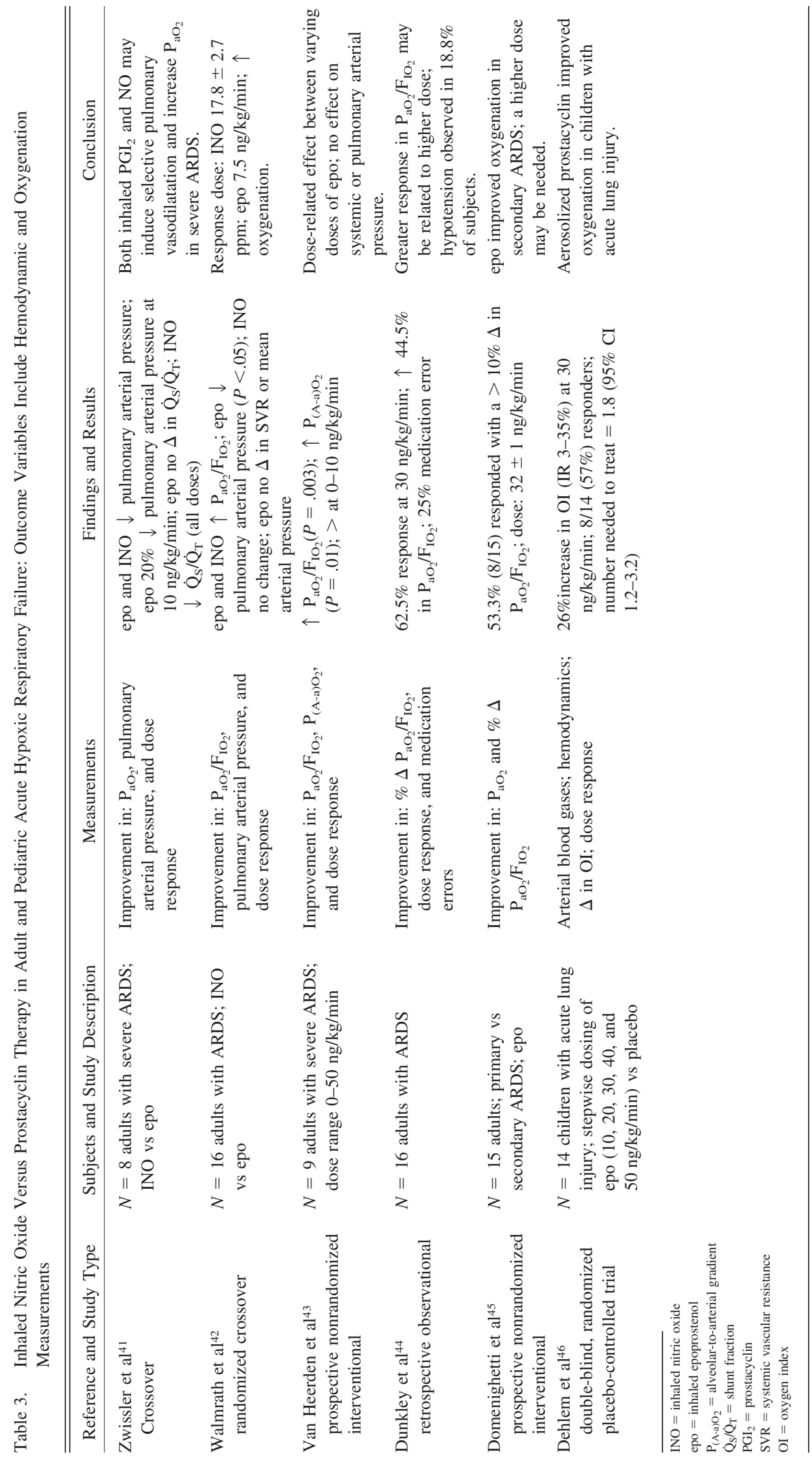




\section{InHaled Pulmonary Vasodilators IN THE PICU}

evidence base, and safety profile. For the purpose of this review, each area will be discussed with emphasis on pediatric populations.

\section{Pharmacodynamics and Dosing}

Prostacyclin is a naturally occurring prostaglandin produced primarily by endothelial cells of the vascular intima and is a known antiregulatory and potent vasodilator. ${ }^{53}$ Epoprostenol, iloprost, and treprostinil increase the concentration of cyclic adenosine monophosphate in smooth muscle cells of the vascular endothelium. ${ }^{54}$ In contrast, INO modulates vasodilatation through stimulation of soluble guanylate cyclase, producing cyclic guanosine monophosphate. ${ }^{54}$ Other clinical characteristics include inhibition of platelet activation, inhibition of leukocyte activation, adhesion, and antiproliferation. ${ }^{54}$ These effects provide theoretical benefits in the treatment of pediatric ARDS. Prostacyclin preferentially enhances the cyclic guanosine monophosphate axis activity, increasing endogenous surfactant production, a characteristic not found with INO. ${ }^{55,56}$ Pathogenesis of ARDS results in worsening pulmonary compliance and oxygenation from increasing lung water. ${ }^{38}$ Protein-rich exudate contained in the alveolus inactivates surfactant proteins, worsening lung compliance, leading to atelectasis and intrapulmonary shunting. ${ }^{38}$ Increasing surfactant production may decrease the need for toxic ventilator settings, thus limiting the risk of barotrauma, atelectrauma, and volutrauma. Additionally, prostacyclin have been found to suppress the synthesis of tumor necrosis factor $\alpha$ in activated monocytes, a cytokine implicated in the pro-inflammatory state in ARDS. ${ }^{56,57}$ The significant expression of interleukin-6, -1 , and -10 and tumor necrosis factor $\alpha$-associated ARDS may result in the suppression of prostacyclin release, which calls into question whether supplementation of prostacyclin may be beneficial during the management of pediatric ARDS. ${ }^{57}$

\section{Epoprostenol Sodium}

The FDA cleared epoprostenol sodium in 1995 for longterm intravenous management of primary pulmonary hypertension in New York Heart Association Class III and Class IV patients not responding to conventional therapy (http://www.accessdata.fda.gov/drugsatfda_docs/nda/ 2000/20-444S003_Flolan_Corres.pdf, Accessed March 3, 2017). Intravenous administration of epoprostenol has been associated with worsening ventilation/perfusion mismatch, tachycardia, hypotension, inhibition of platelet aggregation, and taxiphylaxsis. ${ }^{58}$ Some have postulated that the continuous nebulization of the medication may minimize or even eliminate these adverse events. ${ }^{53,54}$ Epoprostenol was never intended for inhalational applications and is only available in an intravenous preparation. The high $\mathrm{pH}$ of epoprostenol is potentially caustic to the airways and may result in direct lung injury. For this reason, nebulization of prostacyclin analogs approved and available in inhalational preparations should only be considered for this application. Moreover, continuous aerosolized administration of epoprostenol creates potential technical and physiologic patient safety risks.

Several small studies have evaluated the hemodynamic effect of continuous inhalation of epoprostenol in children. Dahlem et al, ${ }^{46}$ in a small prospective trial, failed to demonstrate any adverse effects in children $(<18$ y of age) receiving inhaled epoprostenol. Conversely, Brown et al ${ }^{59}$ retrospectively reviewed the use of epoprostenol for the treatment of acute pulmonary hypertension. In this cohort, $30 \%$ of subjects experienced at least one adverse effect, with the most common event being a decrease in systolic blood pressure requiring fluid boluses or vasoactive agents. ${ }^{59}$ Of the 6 subjects, 5 were neonates, which led the authors to conclude that there is a greater incidence of adverse events in infants younger than $30 \mathrm{~d} .{ }^{59}$ These findings may be related to volume distribution, surface area/body mass ratios, and the absorption kinetics found in pediatric compared with neonatal populations. Therefore, the use of aerosolized epoprostenol in neonates necessitates more aggressive critical care monitoring. ${ }^{59}$

Ideal dosing of inhaled epoprostenol in the pediatric population remains unclear, with the highest quality evidence being obtained from the only prospective randomized controlled trial by Dahlem et al. ${ }^{46}$ That group evaluated the change in oxygenation measured by OI after doses of $10,20,30,40$, and $50 \mathrm{ng} / \mathrm{kg} / \mathrm{min}$, compared with a placebo. ${ }^{46}$ They demonstrated a significant improvement in OI at $30 \mathrm{ng} / \mathrm{kg} / \mathrm{min} .{ }^{46}$ Moreover, there was a trend toward significance at doses of 20,40 , and $50 \mathrm{ng} / \mathrm{kg} / \mathrm{min} .{ }^{46}$ The group also demonstrated a bell-shaped response curve regarding oxygenation improvement, which may help to identify peak dosing in the pediatric ARDS population.

Aerosolized prostacyclin has been shown to be effective in improving oxygenation and lower pulmonary vascular resistance in children with acute hypoxic respiratory failure and congenital heart disease. ${ }^{19,46,57,59-62}$ Dahlem et al ${ }^{46}$ reported a $26 \%$ improvement in OI compared with the placebo group. In terms of response, the group calculated the number needed to treat to observe a $20 \%$ increase in OI is one ${ }^{46}$ This point is interesting because INO possesses a significant rate of non-response in this patient population, which may result from an inability to achieve optimal ventilation, complicated by lung water, atelectasis, and lobular consolidation, contributing to a need for additional critical care intervention over $24-48 \mathrm{~h}$ to achieve optimal ventilation status. Limitations of the study included a small data set, non-homogeneous lung injury etiologies, insufficient power to assess mortality outcomes, and a lack of 


\section{InHaled Pulmonary Vasodilators IN THE PICU}

secondary outcomes, such as duration of mechanical ventilation or hospital costs. ${ }^{46}$

Brown et al ${ }^{59}$ retrospectively evaluated the efficacy of inhaled epoprostenol for the management of acute pulmonary hypertension in 20 subjects (13 neonates and 7 pediatrics $)<18 \mathrm{y}$ of age. The authors reported a significant improvement in OI in the neonatal group $(25.6 \pm 16.3 \mathrm{vs}$ $14.5 \pm 13.6, P=.02) .{ }^{59}$ However, improvement was not observed in children $>30 \mathrm{~d}$ of age $(29.6 \pm 15.3 \mathrm{vs}$ $25.6 \pm 17.8, P=.56) .59$ The group concluded that neonates may benefit more consistently from inhaled prostacyclin than older children. ${ }^{59}$ They further recommended that more intensive monitoring is warranted when delivering aerosolized prostacyclin therapy. Designed as a pilot study, limitations consistent with the retrospective nature of the study do exist. For example, the study lacked complete data regarding echocardiographic evaluation; subjects did not receive consistent drug administration, with the first subject receiving epoprostenol every $2 \mathrm{~h}$ and the remaining cohort being administered continuous nebulization; and the cohort consisted of a non-homogeneous patient population, including neonates and children older than $30 \mathrm{~d} .{ }^{59}$ For these reasons, the results should be interpreted with caution, which further supports the need for large prospective controlled studies addressing the effectiveness of prostacyclin in pediatric acute hypoxic respiratory failure.

\section{Iloprost}

Iloprost is a prostacyclin analog pharmacologically similar to epoprostenol. Compared with epoprostenol, iloprost has lower viscosity, greater stability, more physiologic $\mathrm{pH}$, and a longer half-life (20-30 min), all of which better facilitate nebulization. ${ }^{54}$ Iloprost inhalational solution $(10 \mu \mathrm{g} / \mathrm{mL})$ was cleared by the FDA in 2004 for treatment of pulmonary arterial hypertension (World Health Organization Group I) (http://www.accessdata.fda.gov/drugsatfda docs/nda/2004/21-779_Ventavis_approv.pdf, Accessed March 3, 2017). Iloprost's longer half-life has been associated with an increased risk of arterial hypotension from systemic spillover when compared with INO, leading to the recommendation of intermittent delivery of iloprost rather than continuous nebulization. . $3,58,60,63$ Currently, no evidence exists regarding the benefit of continuous nebulization compared with intermittent delivery of iloprost during the treatment of acute hypoxemic respiratory failure. Intermittent delivery limits the potential risks associated with continuous nebulization, which include but are not limited to inadvertent medication-line disconnection and/or misconnection, delivery interruption, and ventilator malfunction resulting from sticky properties of the drug. ${ }^{61}$

In contrast to epoprostenol, iloprost dosing is different, with optimal dosing remaining undefined in the pediatric critical care setting. The recommended dose for daily management of chronic pediatric pulmonary hypertension is 2.5-5 $\mu \mathrm{g} / \mathrm{dose}$, administered 5-9 times/d up to a maximum dose of $45 \mu \mathrm{g}\left(5 \mu \mathrm{g} /\right.$ dose 9 times daily). ${ }^{53,54}$ In the pediatric acute care setting, iloprost doses ranged from 0.5 to $2 \mu \mathrm{g} / \mathrm{kg} /$ dose with dose intervals between $30 \mathrm{~min}$ and 2 h. ${ }^{47,64,65}$ Rimensberger et al ${ }^{47}$ reported that inhaled iloprost at a dose of $25 \mathrm{ng} / \mathrm{kg} / \mathrm{min}$ for $10 \mathrm{~min}$ was equally effective as INO at selectively decreasing pulmonary vascular resistance. They further demonstrated that iloprost at this dose increases plasma cyclic adenosine monophosphate concentrations from baseline $(P<.05)$ in pediatric subjects who underwent cardiopulmonary bypass surgery. ${ }^{47}$ In a similar patient population, Loukanov et al ${ }^{64}$ demonstrated the favorable safety profile of nebulized iloprost at a dose of $0.5 \mu \mathrm{g} / \mathrm{kg}$ delivery every $2 \mathrm{~h}$. The group did not witness any adverse events, including bleeding complications. ${ }^{64}$

Further investigation is needed to better comprehend best-practice delivery of inhaled vasoactive agents, such as iloprost, because much variation exists in the literature regarding delivery methodology, administration technique, and dose (Table 4). Questions remain surrounding the ideal location for administration (ie, at the Y-piece or before the humidifier) and evaluation of different nebulizers used to administer these agents, in terms of particle size, aerosol output, and dose delivered. Diblasi et $\mathrm{al}^{67}$ evaluated the in vitro effectiveness of iloprost delivery during conventional and high-frequency oscillatory ventilation (HFOV) in a neonatal test-lung model. A vibrating mesh nebulizer was placed proximal to the Y-piece (inspiratory limb) between the humidifier temperature probe and the Y-piece to test conventional ventilation, between the ventilator circuit and endotracheal tube for HFOV, and between the ventilator and the humidifier to evaluate distal nebulizer placement. ${ }^{67}$ Iloprost was quantified using liquid chromatography with the collection filters placed at the distal end of the endotracheal tube. ${ }^{67}$ The group reported greater dose delivery with the nebulizer placed proximal to the airway in both conventional and HFOV modes. ${ }^{67}$ Drug delivery from the proximal position during HFOV was 3 -fold greater when compared with proximal position during conventional ventilation. ${ }^{67}$ The authors concluded that clinicians should avoid placing the nebulizer between the ventilator and humidifier during neonatal ventilation. ${ }^{67}$ The in vitro evidence supports intermittent delivery of iloprost via a vibrating mesh nebulizer during simulated neonatal mechanical ventilation. ${ }^{67}$ Given these data, several questions remain. First, does the increased dose delivery observed in the HFOV model demonstrate ongoing limitations of aerosol delivery during conventional mechanical ventilation? Should dosing be augmented to ensure that a therapeutic dose is delivered, since only $10.74 \%$ of the nominal dose ( $5 \mu \mathrm{g}, 0.5 \mathrm{~mL}$ ) was delivered in this mode? Second, does 


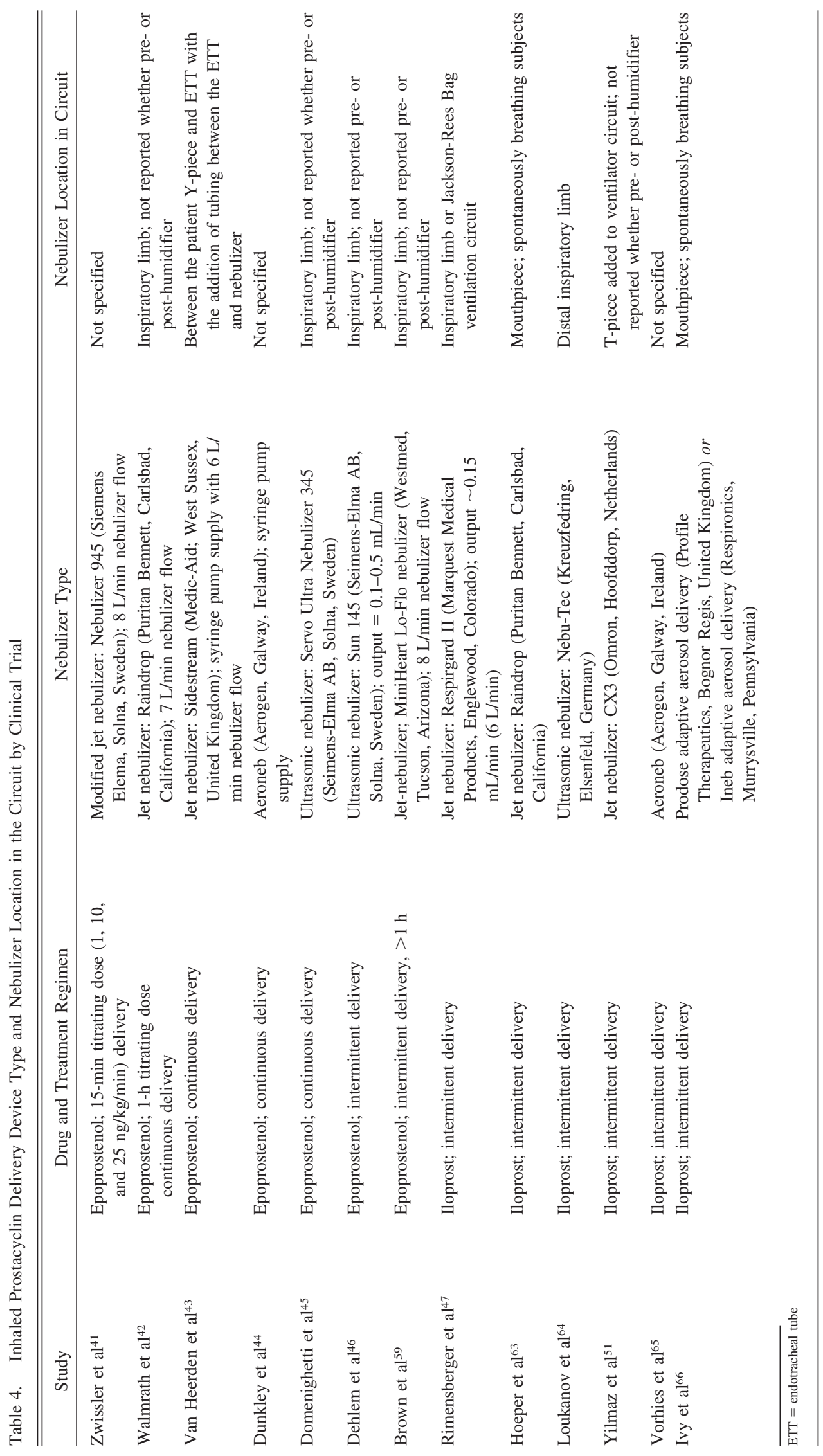




\section{InHaled Pulmonary Vasodilators IN THE PICU}

large tidal breath via a larger endotracheal tube (ie, pediatric population) affect drug delivery? Finally, more work is needed to better understand drug delivery and particle size in standard jet nebulizers, because their functional properties may greatly affect the delivery characteristics.

Pulmonary hypertension is a known complication before and after repair of congenital cardiac defects. Inhalational administration of iloprost has been shown to improve oxygenation and decrease pulmonary vascular resistance in children with congenital heart disease. ${ }^{47,64,65}$, Rimensberger et $\mathrm{al}^{47}$ compared INO with iloprost for the treatment of secondary pulmonary hypertension in children with congenital heart disease. They reported that 25 $\mathrm{ng} / \mathrm{kg} / \mathrm{min}$ of iloprost was equally effective as INO at selectively decreasing pulmonary vascular resistance. ${ }^{47}$ Using a prospective crossover design, the authors compared subjects either in the catheterization laboratory or immediately following surgical repair in the ICU with documented elevated pulmonary vascular resistance. Response was measured using the pulmonary vascular resistance/systemic vascular resistance ratio at baseline, $10 \mathrm{~min}$ after INO initiation, baseline, $10 \mathrm{~min}$ after administration of iloprost, baseline, and $10 \mathrm{~min}$ following delivery of combined therapy. ${ }^{47}$ It was found that INO $(0.48 \pm 0.38$ to $0.27 \pm .016, P<.001)$ and iloprost $(0.49 \pm 0.38$ to $0.26 \pm 0.11, P<.05)$ effectively decreased the pulmonary vascular resistance/systemic vascular resistance ratio from baseline. ${ }^{47}$ No benefit was found during the combined administration of the 2 therapies. ${ }^{47}$ The authors acknowledged several limitations of their study. First, iloprost was always administered after INO because of its longer half-life. Second, whereas the group confirmed that hemodynamics returned to baseline, the potential interaction between INO-induced and iloprost vasodilation effect on the epithelium cannot be ruled out. ${ }^{47}$ Finally, the group did not perform a dose-response evaluation, which cannot rule out the dose-dependent effect on additional decreases in pulmonary vascular resistance/systemic vascular resistance ratio. ${ }^{47}$ This is important to note, because some have hypothesized that smaller-sized ventilator systems may result in greater drug "rainout" that may limit adequate dosing in children. ${ }^{68}$

Vorhies et $\mathrm{al}^{65}$ validated the findings of Rimensberger et $\mathrm{al}^{47}$ in a similar population. They retrospectively evaluated the transition from INO to inhaled iloprost in 7 subjects with postoperative pulmonary hypertension. No differences were found in pulmonary artery pressure $(P=.27)$ and systemic arterial pressure $(P=.25)$ when comparing INO and iloprost. ${ }^{65}$ Most notably, it was found that the pulmonary artery pressure/systemic arterial pressure ratio decreased following the transition to inhaled iloprost (from 0.61 to $0.49, P=.03$ ). ${ }^{65}$ No adverse events or complications were reported in this small data set. ${ }^{65}$ The study had several limitations centered on the small sample size and retrospective chart review design. Collected vari- ables only included clinically relevant parameters, limiting the assessment of potentially important characteristics. In addition, the small sample size presents the risk of sampling bias.

\section{Treprostinil}

Inhalational administration of treprostinil received FDA clearance in 2009 for patients with World Health Organization Group I pulmonary arterial hypertension and functional class III symptoms to improve exercise capacity. ${ }^{62}$ The agent is a chemically stable prostacyclin analog similar to iloprost but with a longer elimination half-life of $4 \mathrm{~h}$ and more favorable administration schedule. ${ }^{69}$ Recommended dosing for treprostinil is 4 times/d with a target dose of 9 breaths/treatment session, compared with the maintenance regimen for iloprost of 6-9 doses (inhalational)/d with a minimum of $2 \mathrm{~h}$ between treatments. Dosage for pediatric patients is 3 breaths ( $18 \mu \mathrm{g} /$ treatment) to 9 breaths $(54 \mu \mathrm{g} /$ treatment $)$ per treatment 4 times $/ \mathrm{d} .{ }^{70}$ The increased half-life and intermittent delivery regime also limits the potential risk of rebound pulmonary hypertension resulting from the abrupt discontinuation of therapy. This has significant potential benefit when compared with epoprostenol or INO.

Treprostinil is administered via the Opti-Neb, a handheld ultrasonic, single-breath nebulizer, which delivers $6 \mu \mathrm{g} / \mathrm{breath}$. The device is designed specifically for subacute settings, creating barriers to its application during invasive mechanical ventilation. Patel et al ${ }^{68}$ evaluated the delivery of a standard dose of treprostinil via an in vitro model. Using a standard jet nebulizer with $10 \mathrm{~L} / \mathrm{min}$, the group tested dose delivery in 2 modern ventilators. The group demonstrated that the nebulizer output was linear for $6 \mathrm{~min}$, delivering a mean $\pm \mathrm{SD}$ inhaled dose of $72.2 \pm 16.5 \mu \mathrm{g}$ (range 47.2-98.6). ${ }^{68}$ It was concluded that is possible to deliver aerosolized treprostinil at controlled doses via a mechanical ventilator. 68 The authors stressed that the outlined conditions must be precisely followed because variation and the presence of a humidifier or inline heat and moisture exchanger may augment dose delivery. ${ }^{68}$ The presence of humidity may affect therapy because the effect may reduce aerosol delivery. ${ }^{71}$ These aspects must be accounted for when considering the delivery of treprostinil or any aerosolized medication in mechanically ventilated patients. Additional work is needed to describe drug delivery best practices regarding nebulizer types, dose accuracy, breathing pattern variation, and brand of ventilators. ${ }^{68}$

Inhaled treprostinil has been shown to be safe and efficacious in adults, with a majority of evidence addressing quality-of-life- and exercise-based measures. A small body of evidence in the pediatric population seems to suggest similar findings. Krishnan et $\mathrm{al}^{70}$ describe the safety and 
efficacy of inhaled treprostinil in a retrospective analysis of 29 children with documented Group 1 pulmonary arterial hypertension. Therapy was initiated at 3 breaths 4 times/d, titrated as tolerated to a maximum of 9 breaths 4 times/d. ${ }^{70}$ Treprostinil was delivered via the Opti-Neb handheld ultrasonic nebulizer. The group reported improvement in World Health Organization functional class in 19 of the 29 subjects; significant improvement in exercise capacity, with 6-min walk distance increasing from $455.7 \pm 71.5$ to $498 \pm 70 \mathrm{~m}(P=.01)$; and peak oxygen consumption increasing from $25.5 \pm 10.2$ to $27.4 \pm 10$ $\mathrm{mm} \mathrm{Hg}(P=.04) .^{70}$ Treprostinil therapy was discontinued in 4 subjects secondary to symptoms of cough and bronchospasm and progression of pulmonary arterial hypertension. ${ }^{70}$ Documented mild adverse effects included cough and sore throat, which did not result in discontinuation of therapy. ${ }^{70}$ The authors concluded that treprostinil was associated with improved exercise capacity and functional class measures and had an acceptable safety profile..$^{70}$ No pediatric-specific studies exist regarding the effect of treprostinil on oxygenation measurement, right-heart pressure, or outcome in the intensive care setting.

\section{Safety Considerations During the Delivery of Inhaled Pulmonary Vasodilators}

Administration of INO is not without risk. A short halflife creates the risk of rebound pulmonary hypertension resulting from the abrupt cessation of therapy. Interruption of delivery can result from mechanical equipment failure; exhaustion of gas supply; kinking, disconnection, or obstruction of the delivery line; and failure to connect the resuscitation bag to an INO supply. The FDA mandates a backup delivery system for continuous inhaled delivery of pulmonary vasoactive medications. Commercially available devices have such systems and alarms incorporated into their design; however, the risk remains. In addition, during times of high usage volume and inclement weather, a potential for limited access to delivery systems does exist. Size of the delivery systems adds logistical challenges when transferring a patient within the hospital. Moving a patient for a diagnostic procedure(s) creates the need to push a device with the patient to the location of the procedure. This increases the risk of accidental extubation and abrupt interruption of delivery.

Aerosolization of these potent medications is not without risk, as specific technical sources of error, adverse effects, and physiologic deterioration have been reported. ${ }^{46,60,66} \mathrm{~A}$ recent independent third-party report described the potential sources of technical error during the continuous nebulization of epoprostenol occurring in (1) infusion pumps, (2) nebulizers, and (3) ventilators. ${ }^{61}$ Sources of technical error may result from the following. ${ }^{61}$ (1) Supplying medication to the nebulizer via an infusion pump can lead to inadvertent misconnection and patient overdose. Specifically, an infusion pump line that connects to the nebulizer can be inadvertently connected to the patient's intravenous line. The intravenous dose is 2 $\mathrm{ng} / \mathrm{kg} / \mathrm{min}$, where the inhalational dose may be as high as $50 \mathrm{ng} / \mathrm{kg} / \mathrm{min}$, a 25 -fold increase in dose, resulting in serve hypotension and/or death. (2) There may be no alarms to alert clinicians if the therapy has been interrupted. Interruption may result in physiologic deterioration from a relatively short pause in therapy. Electrically driven nebulizers may default from continuous to intermittent delivery modes when power is interrupted. The delivery mode must be assessed in the event of power loss to ensure appropriate administration. (3) Ventilator component malfunction as a result of aerosolized medication can result in increased expiratory resistance, resulting in a failure to exhale and auto-PEEP, which may result in pneumothorax. Standard jet nebulizers add additional flow to the ventilator circuit that may alter ventilator function.

In addition to these areas of focus, other considerations must be addressed regarding the safe administration of prostacyclin. They include labeling of all infusion lines, ensuring availability of backup equipment to quickly reestablish therapy in the event of equipment failure, developed policies for the proper storage and handling of the medications, and understanding of the effect of additional gas flow on delivery monitors and associated alarms before using a pneumatically driven nebulizer. ${ }^{61}$ The sticky properties of the medication and infusion rates may also impair drug delivery when it is administered via a vibrating mesh nebulizer and must be considered because they may result in fluctuations in dose delivery.

In the pediatric patient population, inhalational administration of epoprostenol has been thought to cause direct injury to the lung epithelium due to being diluted in an alkaline base ( $\mathrm{pH} \sim 10)$. Exposure to a high-pH solution may worsen underlying lung disease, negatively affecting pulmonary mechanics and ventilation status. Iloprost is diluted in a neutral base, which some have hypothesized may be less harmful to the lung epithelium. This should be considered when considering administration of prostacyclin.

Clinical deterioration and physiologic adverse effects during the administration of prostacyclin have been reported. ${ }^{60,72}$ Ivy et al ${ }^{66}$ evaluated the short- and long-term effects of inhaled iloprost in children with chronic pulmonary hypertension. The group reported that the most common adverse effects were headache (36\%), cough (23\%), and dizziness (14\%), all of which improved within several days of the start of therapy. ${ }^{66}$ Two subjects without prior history of lung disease were discontinued from therapy as a result of persistent cough, dyspnea, and room air desaturation immediately following iloprost inhalation. ${ }^{66}$ Two additional subjects demonstrated lower airway obstruction 


\section{InHaled Pulmonary Vasodilators IN THE PICU}

several months following the initiation of iloprost therapy as well. ${ }^{66}$ The authors concluded that inhaled iloprost may induce bronchoconstriction and must be considered when administering in children. ${ }^{70}$ Conversely, others have failed to validate these findings. ${ }^{46,73}$ Dahlem et al ${ }^{46}$ assessed the expiratory limb flow/volume curves in 9 children randomized to receive aerosolized epoprostenol with acute lung injury. They reported no change in the flow/volume curve during the study period. ${ }^{46}$ Because of limited data regarding the effect of prostacyclin airway sensitivity, steps must be taken to monitor for airway reactivity during administration of aerosolized prostacyclin and its analogs.

The vasoactive properties of prostacyclin possess the potential to result in systemic hypotension, which is relatively common when administered intravenously. ${ }^{54}$ Inhalational delivery of these agents has been found to decrease the risk of systemic spillover and resulting hemodynamic adverse effects. ${ }^{54}$ Distance between the alveolus and smooth muscle cell is approximately $10 \mu \mathrm{m}$ at most, which facilitates easy transfer of the inhaled drug. ${ }^{54}$ This results in pulmonary selectivity similar to inhaled nitric oxide, with no or little effect on the systemic circulation.

Continuous delivery of any pulmonary vasoactive agent, whether intravenously or by inhalational administration, presents a risk of disastrous consequence in the event of abrupt discontinuation of delivery. These include increasing pulmonary artery pressure and worsening oxygenation; both may be refractory and may require the initiation of extracorporeal life support intervention. This was of significant concern during the 1999 FDA clearance of INO. ${ }^{72}$ In January 2000, the FDA published a guidance document for nitric oxide delivery devices regarding the need for safety and monitoring features. These features include the continuous monitoring of $\mathrm{NO}, \mathrm{NO}_{2}$, and $\mathrm{O}_{2}$ delivery; a backup delivery system; sensors that monitor and alarm when $\mathrm{NO}$ or $\mathrm{NO}_{2}$ concentrations are out of a set range; and a backup power supply (http://www.fda.gov/downloads/MedicalDevices/ DeviceRegulationGuidence/GuidenceDocuments/ ucm073767.pdf, Accessed August 5, 2016). Current INO delivery systems (eg, INOMAX DS ${ }_{\mathrm{ir}}$, INOmax DS, and INOvent, INO Therapeutics, Hampton, New Jersey) have integrated analyzers to consistently monitor $\mathrm{NO}, \mathrm{NO}_{2}$, and $\mathrm{O}_{2}$ delivery and also have both audible and visual alarms notifying users of cessation of drug delivery and/or incorrect drug concentration. They also include a backup delivery system, backup NO cylinder ( 2 cylinders maintained with the system at all times), and internal battery in event of a power failure. These devices are the only systems for the continuous delivery of inhaled pulmonary vasodilators that comply with all FDA delivery device requirements. It must be noted that nebulization of prostacyclin and its analogs does not affect the concentrations of $\mathrm{NO}$ or $\mathrm{NO}_{2}$.
Therefore, only $\mathrm{F}_{\mathrm{IO}_{2}}$ needs to be monitored with particular attention to gas source $\mathrm{F}_{\mathrm{IO}_{2}}$ when using gas power nebulizers. If used, these systems must have the ability to monitor combined $\mathrm{F}_{\mathrm{IO}_{2}}$ during administration.

The use of inhaled vasoactive agents, such as epoprostenol, iloprost, and treprostinil, continues to grow as a less costly alternative to inhaled nitric oxide. Evidence suggests that these agents are equally as effective as INO at increasing oxygenation measures and decreasing pulmonary vascular resistance in children with acute hypoxic failure and cardiac disease. Epoprostenol is not approved for inhalational applications, and its short half-life requires continuous aerosol delivery. Continuous aerosol delivery systems are often home-grown, lack alarms notifying clinicians of medication disconnection, have a propensity to cause ventilator malfunction, and possess a significant risk of either over- or underdosing of the medication. The more stable prostacyclin analogs iloprost and treprostinil have longer duration of action compared with INO and epoprostenol, allowing for intermittent treatment regimes. Intermittent delivery alleviates the need for continuous administration but is equally effective, increasing patient safety and possibly providing cost and work flow benefits. However, nebulization of these agents is not without risk, which must be considered before administration to ensure accurate dose delivery. Future work is needed to understand the effectiveness of both iloprost and treprostinil in pediatric ARDS and pediatric cardiac disease populations.

\section{Summary}

Only FDA-cleared inhalational pulmonary vasoactive agents should be considered for the treatment of pulmonary hypertension. Those currently cleared include INO (neonatal patients $>34$ weeks gestation), iloprost, and treprostinil for inhalational administration. No high-level evidence exists supporting the routine use of INO in the pediatric population. However, INO may be considered as a rescue therapy in pediatric severe acute respiratory hypoxic failure and right-sided heart failure. More study is needed to ascertain the effect of INO as it relates to homogeneous pathologies, its effect on long-term outcome, and cost/benefit regarding stay and morbidity.

Epoprostenol should not be considered for inhalational administration because it is only available in and approved for intravenous administration and presents significant technical and patient safety concerns. Both iloprost and treprostinil are available in inhalation preparations and should be considered before the use of epoprostenol. Inhalational preparation and intermittent treatment schedule make these agents acceptable alternatives to aerosolized epoprostenol and potentially INO. Additional research is required regarding aerosolized vasoactive agents and their efficacy in the pediatric population. One area of particular interest 


\section{InHALEd PUlmonary Vasodilators IN THE PICU}

is the potential use of inhaled prostacyclin analogs in patients unresponsive to INO and/or those requiring longterm nitric oxide therapy. It is critical to include acceptable time frames for cardiovascular stabilization and ventilation optimization, because lung-protective strategies may ultimately affect therapy response and outcome in pediatric ARDS. The work may help to identify acceptable inclusion criteria, measurable responses, therapeutic goals, and management strategies.

\section{REFERENCES}

1. Bhatraju P, Crawford J, Hall M, Lang JD. Inhaled nitric oxide: current clinical concepts. Nitric Oxide 2015;50:114-128.

2. DiBlasi RM, Myers TR, Hess DR. Evidence-based clinical practice guidelines: inhaled nitric oxide for neonates with acute hypoxic respiratory failure. Respir Care 2010;55(12):1717-1745.

3. Todd Tzanetos DR, Housley JJ, Barr FE, May WL, Landers CD. Implementation of an inhaled nitric oxide protocol decreases direct cost associated with its use. Respir Care 2015;60(5):644-650.

4. Pierce CM, Peters MJ, Cohen G, Goldman AP, Petros AJ. Cost of nitric oxide is exorbitant (editoral). BMJ 2002;325(7359):336.

5. Gattinoni L, Pelosi P, Suter PM, Pedoto A, Vercesi P, Lissoni A. Acute respiratory distress syndrome caused by pulmonary and extrapulmonary disease: different syndromes. Am J Respir Crit Care Med 1998;158(1):3-11.

6. Abman SH, Griebel JL, Parker DK, Schmidt JM, Swanton D, Kinsella JP. Acute effect of inhaled nitric oxide in children with severe hypoxic respiratory failure. J Pediatr 1994;124(6):881-888.

7. Okamoto K, Hamaguchi M, Kukita I, Kikuta K, Sato T. Efficacy of inhaled nitric oxide in children with ARDS. Chest 1998;114(3):827833.

8. Sheridan BL, Zapol WM, Ritz RH, Tompkins RG. Low-dose inhaled nitric oxide in acutely burned children with profound respiratrory failure. Surgery 1999;126(5):856-862.

9. Fioretto JR, de Moraes MA, Bonatto RC, Ricchetti SMQ, Carpi MF. Acute and sustained effect of early administration of inhaled nitric oxide to children with acute respiratory distress syndrome. Pediatr Crit Care Med 2004;5(5):469-474.

10. Demirakça S, Dötsch J, Knothe C, Magsaam J, Reiter HL, Bauer J, Kuehl PG. Inhaled nitric oxide in neonatal and pediatric acute respiratory distress syndrome: dose response, prolonged inhalation, and weaning. Crit Care Med 1996;24(11):1913-1919.

11. Bronicki RA, Fortenberry J, Schreiber M, Checchia PA, Anas NG. Multicenter randomized controlled trial of inhaled nitric oxide for pediatric acute respiratory distress syndrome. J Pediatr 2015;166(2): 365-369.e1.

12. Bernard GR, Artigas A, Brigham KL, Carlet J, Falke K, Hudson L, et al. The American-European consensus conference on ARDS: definitions, mechanisms, and relevant outcomes, and clinical trial coordination. Am J Respir Crit Care Med 1994;149(3 Pt 1):818-824.

13. Slutsky AS, Tremblay LN. Multiple system organ failure: is mechanical ventilation a contributing factor? Am J Respir Crit Care Med 1998;157(6 Pt 1):1721-1725.

14. Jaecklin T, Otulakowski G, Kavanagh BP. Do soluble mediators cause ventilator-induced lung injury and multi-organ failure. Intensive Care Med 2010;36(5):750-757.

15. Maniatis NA, Kotanidou A, Catravas JD, Orfanos SE. Endothelial pathmechonisms in acute lung injury. Vascul Pharmacol 2008;49(4): 119-133.

16. Finigan JH. The coagulation system and pulmonary endothelial function in acute lung injury. Microvasc Res 2009;77(1):35-38.
17. Ware LB, Fang X, Matthay MA. Protein $C$ and thrombimodulin in human acute lung injury. Am J Physiol Lung Cell Mol Physiol 2003;285(3):L514-L521.

18. Jin RC, Voetsch B, Loscalzo J. Endogenous mechanisms of inhibition of platelet function. Microcirculation 2005;12(3):247-258.

19. Afshari A, Brok J, Moller AM, Wetterslev J. Inhaled nitric oxide for acute respiratory distress syndrome (ARDS) and acute lung injury in children and adults (review). Cochrane Database Syst Rev 2016;(6): CD002787.

20. Sokol J, Jacobs SE, Bohn D. Inhaled nitric oxide for acute hypoxic respiratory failure in children and adults: a meta-analysis. Anesth Analg 2003;97(4):989-998.

21. Smith LS, Zimmerman JJ, Martin TR. Mechanisms of acute respiratory distress syndrome in children and adults: a review and suggestions for future research. Pediatr Crit Care Med 2013;14(6):631643.

22. Kneyber M, Zhang H, Slusky A. Similarity and differences between children and adults. Am Respir Crit Care Med 2014;190(3):258-265.

23. Rubenfeld GD, Caldwell E, Peabody E, Weaver J, Martin DP, Neff $\mathrm{M}$, et al. Incidence and outcomes of acute lung injury. N Engl J Med 2005;353(16):1685-1693.

24. Santschi M, Jouvet P, Leclerc F, Gauvin F, Newth CJ, Carroll CL, et al. Acute lung injury in children: therapeutic practice and feasibility of international clinical trials Pediatr Crit Care Med 2010;11(6):681689.

25. Gupta P, Richardson T, Hall M, Bertoch D, Hebbar KB, Fortenberry JD, Wetzel RC. Effect of inhaled nitric oxide on outcomes in children with acute lung injury: Propensity matched analysis from a linked database. Crit Care Med 2016;44(10):1901-1909.

26. Hoffman JI, Rudolph AM, Heymann MA. Pulmonary vascular disease with congenital heart lesions: pathologic features and causes. Circulation 1981;64(5):873-877.

27. Clapp S, Perry BL, Farooki ZQ, Jackson WL, Karpawich PP, Hakimi $\mathrm{M}$, et al. Down's syndrome, complete atrioventricular canal, and pulmonary obstructive disease. J Thorac Cardiovasc Surg 1990; 100(1):115-121.

28. Wessel DL, Adatia I, Giglia TM, Thompson JE, Kulik TJ. Use of inhaled nitric oxide and acetylcholine in evaluation of pulmonary hypertension and endothelial function after cardiopulmonary bypass. Circulation 1993;88(5 Pt 1):2128-2138.

29. Curran RD, Mavroudis C, Backer CL, Sautel M, Zales VR, Wessel DL. Inhaled nitric oxide for children with congenital heart disease and pulmonary hypertension. Ann Thorac Surg 1995;60(6):17651771.

30. Miller OI, Tang SF, Keech A, Pigott NB, Beller E, Celermajer DS. Inhaled nitric oxide and prevention of pulmonary hypertension after congenital heart surgery: a randomised double-blind study. Lancet 2000;356(9240): 1464-1469.

31. Day RW, Hawkins JA, Mcgough EC, Crezee KL, Orsmond GS. Randomized controlled study of inhaled nitric oxide after operation for congenital heart disease. Ann Thorac Surg 2000;69(6):1907-1912; discussion 1913.

32. Russell IAM, Zwass MS, Fineman JR, Balea M, Rouine-Rapp K, Brook M, et al. The effect of inhaled nitric oxide on postoperative pulmonary hypertension in infants and children undergoing surgical repair of congenital heart disease. Anesth Analg 1998;87(1):46-51.

33. Morris K, Beghetti M, Petros A, Adatia I, Bohn D. Comparison of hyperventilation and inhaled nitric oxide for pulmonary hypertension after repair of congenital heart disease. Crit Care Med 2000;28(8): 2974-2978.

34. Kallet RH, Branson RD. Should oxygen therapy be tightly regulated to minimize hyperoxia in critically ill patients. Respir Care 2016; 61(6):801-817. 


\section{InHALEd PUlmonary Vasodilators IN THE PICU}

35. Bizzarro M, Gross I, Barbosa FT. Inhaled nitric oxide for the postoperative management of pulmonary hypertension in infants and children with congenital heart disease. Cochrane Database Syst Rev 2014;(7):CD005055.

36. Paulson TE, Spear RM, Peterson BM. New concepts in the treatment of children with acute respiratory distress syndrome. J Pediatr 1995; 127(2):163-175.

37. Sachdeva RC, Guntupalli KK. Acute respiratory distress syndrome. Crit Care Clin 1997;13(3):503-521.

38. Cornfield DN. Acute respiratory distress syndrome in children: physiology and management. Curr Opin Pediatr 2013;25(3):338-343.

39. Tadphale SD, Rettiganti M, Gossett JM, Beam BW, Padiyath A, Schmitz ML, Gupta P. Is administration of nitric oxide during extracorporeal memberane oxygenation associated with improved patient survival. Pediatr Crit Care Med 2016;17(11):1080-1087.

40. Dellinger RP, Trzeciek SW, Criner GJ, Zimmerman JL, Taylor RW, Usansky $\mathrm{H}$, et al. Association between inhaled nitric oxide treatment and long-term pulmonary function in survivors of acute respiratory distress syndrome. Crit Care 2012;16(2):R36.

41. Zwissler B, Kemming G, Habler O, Kleen M, Merkel M, Haller M, et al. Inhaled prostacyclin (PGI2) versus inhaled nitric oxide in adult respiratory distress syndrome. Am J Respir Crit Care Med 1996; 154(6 Pt 1):1671-1677.

42. Walmrath D, Schneider T, Schermuly R, Olschewski H, Grimminger F, Seeger W. Direct comparison of inhaled nitric oxide and aerosolized prostacyclin in acute respiratory distress syndrome. Am J Respir Crit Care Med 1996;153(3):991-996.

43. van Heerden PV, Barden A, Michalopoulos N, Bulsara MK, Roberts BL. Dose-response to inhaled aerosolozed prostacyclin for hypoxemia due to ARDS. Chest 2000;117(3):819-827.

44. Dunkley KA, Louzon PR, Lee J, Vu S. Efficacy, safety, and medication errors associated with the use of inhaled epoprostenol for adults with acute respiratory distress syndrome: a pilot study. Ann Pharmacother 2013;47(6):790-796.

45. Domenighetti G, Stricker H, Waldispuehl B. Nebulized prostacyclin (PGI2) in acute respiratory distress syndrome: impact of primary (pulmonary injury) and secondary (extrapulmonary injury) disease on gas exchange response. Crit Care Med 2001;29(1):57-62.

46. Dahlem P, van Aalderen WM, de Neef M, Dijkgraaf MG, Bos AP. Randomized controlled trial of aerosolized prostacyclin therapy in children with acute lung injury. Crit Care Med 2004;32(4):10551060 .

47. Rimensberger PC, Spahr-Schopfer I, Berner M, Jaeggi E, Kalangos A, Friedli B, Beghetti M. Inhaled nitric oxide versus aerosolized iloprost in secondary pulmonary hypertension in children with congenital heart disease, vasodilator capacity and cellular mechanisms. Circulation 2001;103(4):544-548.

48. Khan TA, Schnickel G, Ross D, Bastani S, Laks H, Esmailian F, et al. A prospective, randomized, crossover pilot study of inhaled nitric oxide versus inhaled prostacyclin in heart transplant and lung transplant recipients. J Thorac Cardiovasc Surg 2009;138(6): $1417-1424$

49. Mulligan C, Beghetti M. Inhaled iloprost for the control of acute pulmonary hypertension in children: a systemic review. Pediatr Crit Care Med 2012;13(4):472-480

50. Rex S, Schaelte G, Metzelder S, Flier S, de Waal EE, Autschbach $\mathrm{R}$, et al. Inhaled iloprost to control pulmonary artery hypertension in patients undergoing mitral valve surgery: a prospective, randomized-controlled trial. Acta Anaesthesiol Scand 2008;52(1): 65-72.

51. Yilmaz O, Kahveci H, Zeybek C, Ciftel M, Kilic O. Inhaled iloprost in preterm infants with severe respiratory distress syn- drome and pulmonary hypertension. Am J Perinatol 2014;31(4): 321-326.

52. McGinn K, Reichert M. A comparison of inhaled nitric oxide versus inhaled epoprostenol for acute pulmonary hypertension following cardiac surgery. Ann Pharmacother 2016;50(1):22-26.

53. Tissot C, Beghetti M. Review of inhaled iloprost for the control of pulmonary artery hypertension in children. Vasc Health Risk Manag 2009;5(1):325-331.

54. Vane JR, Botting RM. Pharmacodynamic profile of prostacyclin. Am J Cardiol 1995;75(3):3A-10A.

55. Rose F, Zwick K, Ghofrani HA, Sibelius U, Seeger W, Walmrath D, Grimminger F. Prostacyclin enhances stretch-induced surfactant secretion in alveolar epithelial type II cells. Am J Respir Crit Care Med 1999;160(3):846-851

56. Eisenhut T, Sinha B, Gröttrup-Wolfers E, Semmler J, Siess W, Endres S. Prostacyclin analogs suppress the synthesis of tumor necrosis factor- $\alpha$ in LPS-stimulated human peripheral blood mononuclear cells. Immunopharmacology 1993;26(3):259-264.

57. Yang G, Hamacher J, Gorshkov B, White R, Sridhar S, Verin A, et al. The dual role of TNF in pulmonary edema. J Cardiovasc Dis Res 2010;1(1):29-36

58. Siobal M. Aerosolized prostacyclins. Respir Care 2004;49(6):640652

59. Brown AT, Gillespie JV, Miquel-Vergas F, Holmes K, Ravekes W, Spevak P, et al. Inhaled epoprostenol therapy for pulmonary hypertension: improves oxygenation index more consistently in neonates than in older children. Pulm Circ 2012;2(1):61-66.

60. Searcy RJ, Morales JR, Ferreira JA, Johnson DW. The role of inhaled prostacyclin in treating acute respiratory distress syndrome. Ther Adv Respir Dis 2015;9(6):302-312.

61. ECRI Institute. ECRI Institute warns of equipment risks associated with use of inhaled epoprostenol [ECRI Exclusive Hazard Report]. March 24, 2016. Plymouth Meeting, Pennsylvania: ECRI Institute.

62. Ferrantino M, White RJ. Inhaled treprostinil sodium for treatment of pulmonary arterial hypertension. Expert Opin Pharmacother 2011; 12(16):2583-2593

63. Hoeper MM, Olschewski H, Ghofrani HA, Wilkens H, Winkler J, Borst MM, et al. A comparison of the acute hemodynamic effects of inhaled nitric oxide and aerosolized iloprost in primary pulmonary hypotension. J Am Coll Cardiol 2000;35(1):176-182.

64. Loukanov T, Bucsenez D, Springer W, Sebening C, Rauch H, Roesch E, et al. Comparison of inhaled nitric oxide with aerosolized iloprost for the treatment of pulmonary hypertension in children after cardiopulmonary bypass surgery. Clin Res Cardiol 2011;100(7):595602 .

65. Vorhies EE, Caruthers RL, Rosenberg H, Yu S, Gajarski RJ. Use of inhaled iloprost for the management of postoperative pulmonary hypertension in congenital heart surgery patients: review of a transitional protocol. Pediatr Cardiol 2014;35(8):1337-1343.

66. Ivy DD, Doran AK, Smith KJ, Mallory GB Jr, Beghetti M, Barst RJ, et al. Short- and long-term effects of inhaled iloprost therapy in children with pulmonary arterial hypertension. J Am Coll Cardiol 2008;51(2):161-169.

67. DiBlasi RM, Crotwell DN, Shen S, Zheng J, Fink JB, Yung D. Iloprost drug delivery during infant conventional and high-frequency oscillatory ventilation. Pulm Circ 2016;6(1):63-69.

68. Patel RB, Smaldone GC, Cuccia AD, Strachan P. In vitro delivery of aerosolized treprostinil via modern mechanical ventilation. J Aerosol Med Pulm Drug Deliv 2013;26(4):200-207. 


\section{InHaled PUlmonary Vasodilators IN THE PICU}

69. Channick RN, Voswinckel R, Rubin LJ. Inhaled treprostinil: a therapeutic review. Drug Des Devel Ther 2012;6:19-28.

70. Krishnan U, Takatsuki S, Ivy DD, Kerstein J, Calderbank M, Coleman E, Rosenzweig EB. Effectiveness and safety of inhaled treprostinil for the treatment of pulmonary arterial hypertension in children. Am J Cardiol 2012;110(11):1704-1709.

71. Dhand R. Aerosol delivery during mechanical ventilation: from basic techniques to new devices. J Aerosol Med Pulm Drug Deliv 2008; 21(1):45-60.
72. Cosa N, Costa E. Inhaled pulmonary vasodilators for persistent pulmonary hypertension of the newborn: safety issues relating to drug administration and delivery devices. Med Devices 2016;9:45-51. doi: 10.2147/MDER.S99601.

73. Piastra M, De Luca D, De Carolis MP, Tempera A, Stival E, Caliandro F, et al. Nebulized iloprost and noninvasive respiratory support for impending hypoxaemic respiratory failure in formally preterm infants: a case series. Pediatr Pulmonol 2012;47(8):757762.

\section{Discussion}

Fedor: I have one comment. This is good information; I actually did a presentation in my marketing class about switching to other inhaled agents. The thing that we see in education on a physician level in terms of actually being able to get them to discontinue the drug. We had a lot of problems with the "if it ain't broke don't fix it" mentality, and we incur a lot of costs based on that.

Kuch: I could not agree more, and I assume that I am dealing with this issue probably as much as you are. From the discussions among the group regarding Todd Tzanetos et al, ${ }^{1}$ which addressed protocolization of INO: What the group did, which was really nice, was that if they were started on INO they were automatically enrolled in the protocol. If the physician didn't want them to be enrolled, they had to write an order for the patient to be opted out of the protocol. In addition, they delegated the RTs [respiratory therapists] with weaning the INO. The second part was that the RTs had specific criteria as to what was considered a response and what was not, which is critical. I feel the success of their work was having therapists manage the protocol so it's automatically defaulted to be enrolled and having good communication with physicians as we do with ventilatordriven protocols. As long as the RTs are educated and understand who are responders and non-responders, they will drive that process and move it forward. That is what we are currently working on, coming up with a process. I don't think we should limit access to INO, which has occurred in some areas; I think we need to have access to nitric oxide. But we also have to understand there are nonresponders; put it in the therapists' hands, and work to wean the therapy when there is no benefit.

Fedor: I think it requires a culture that empowers the therapists to do such things. And the relationships with your physicians as well.

Cheifetz: In a follow-up to your prior comments, I agree with you in concept regarding responders and non-responders. The problem is: How to define a responder? In our institution, one clinician may say that an increase in $\mathrm{S}_{\mathrm{pO}_{2}}$ by $5 \%$ is a responder, while another clinician would want to see a more significant change. We also need to consider markers of response/nonresponse beyond oxygenation. For example, in the post-cardiopulmonary bypass population, the issue is often more right-ventricular dysfunction than a failure to adequately oxygenate. While helpful, echocardiography is often more qualitative than quantitative. So, what are your thoughts and recommendations regarding the best approach to objectively define an INO responder?

Kuch: Some data suggest a $20 \%$ increase in $\mathrm{P}_{\mathrm{aO}_{2}} / \mathrm{F}_{\mathrm{IO}_{2}}$ in acute respiratory failure. This is an area we struggle with as well: Who is a responder and who is a non-responder? I think it might be institutional or an area that can be addressed by a group who defines patient-specific responses, much like oxygenation in the neonatal population: What is the correct saturation, given the level of lung disease? If it's severe lung disease, how do we define adequate response? It may be a moving target, to be honest with you. In terms of the cardiac group, obviously, the ability to monitor central venous pressure is important, and you could assume there would be some relevance. So those children who come off bypass often have central venous pressure monitoring in place, which may add some value. In addition, I think this group is more difficult to evaluate; thus, there are only data from 210 subjects, and I don't know if we can make any conclusions from the current literature. Central venous pressure, cardiac output, magnitude of shunting, and measures of that nature may be useful in identifying responders while assessing clinical benefit of the therapy.

Stokes: As we aerosolize these very potent drugs-and you raised safety issues for patients-but do you have any information on safety issues for staff and therapists? And potential environmental exposure that might be an issue?

Kuch: I did not necessarily pull and review the environmental health and safety literature. Anecdotally, there are reports of lightheadedness and staff becoming flushed with nebulization of pulmonary vasodilators. These reports beg the question as to how much the symptoms experienced are directly associated with the agents in question. I think more work needs to be done to better understand the effect of envi- 


\section{Inhaled Pulmonary Vasodilators IN the PICU}

ronmental exposure to aerosolized prostacyclin. However, it is interesting that we don't see a significant number of children becoming hypotensive when it's delivered directly to the respiratory tract, yet there are reports of negative effects in exposed staff. Scavenging of exhaled particulate or the use of filters may be useful in limiting environmental exposure.

Berlinski: A comment about delivery devices. We use vibrating mesh nebulizers for all these studies, and there are lots of data showing that they might not have consistent output. Some are consistent and have good output, and some are significantly different. I think that's something practitioners need to keep in mind, because sometimes the lack of response may not be related to the drug, but to a device that's not working as it should.

Kuch: That's a great point. In fact, evidence seems to suggest the therapeutic pediatric dose is higher than the adult dose. The authors hypothesized the need for increased dosage is related to the size of the pediatric airway and resulting rainout in the endotracheal tube. This may be the reason that $30 \mathrm{ng} / \mathrm{kg} / \mathrm{min}$ is the effective dose being used in children, whereas in adults, the dose is lower. This is just one theory. I did look at some of these studies and the devices used; there's no consistency within the studies. Some are using uniHEART nebs, others are using vibrating mesh; they're using different devices; there's not consistency in the literature. It's a nice area of work to focus on, particularly through particle size assessment: what particle size is being delivered and the potential dose administered. There are advanced techniques to evaluate this topic.

Smallwood: A lot of the data you presented highlighted the lack of evidence INO has for acute hypoxemic respiratory failure or pediatric ARDS. I' $m$ wondering if there are any further analyses stratifying these subjects based on disease severity or sub-cohort characteristics. Is there a smaller, sicker group that could potentially see a benefit? Do you have any insights on that?

Kuch: Yes, there was a study by Dobyns et $\mathrm{al}^{2}{ }^{2}$ where they stratified subjects by primary diagnosis into 5 different groups. They included pneumonia with chronic lung disease, pneumonia without chronic lung disease, immunocompromised children, sepsis, and there was another group, which included trauma. Again, it was small numbers with a total of 108 subjects enrolled. They demonstrated a slight benefit in the immunocompromised subjects in regard to sustained improvement in oxygenation who received INO that they did not witness in any of the other subgroups. Small sample size seems to be an ongoing issue, and how do we undertake a robust-sized trial. That's part of what I was speaking to before, if we take pneumonia or direct ARDS etiologies; truly identify and define that group well and evaluate outcomes; at least you would understand INO's clinical benefit in that particular group.

Walsh: One question about the second point under rescue therapy: Did you present data that showed that it decreases the need for ECMO in a pediatric population? I understand that it does in a neonatal population, but in pediatrics?

Kuch: Yes, this was measured by ECMO-free days and survival without ECMO, and it did seem to increase those measures during long-term lowdose delivery of 5 ppm INO. The benefit was seen when compared with a placebo of $5 \mathrm{ppm}$ nitrogen. Now, this study $^{3}$ wasn't specifically designed for this outcome; I think it was a post hoc finding. However, the subjects who received INO had longer survival without ECMO. Brian, the data from this study are not necessarily as convincing as the neonatal data that demonstrated a reduction in ECMO support in infants treated with INO.

Walsh: Another thing about epoprostenol in particular that worries me is that it was never designed for the respiratory tract, whereas other drugs such as iloprost are. I'd like to see that we don't consider or promote the use of pulmonary vasodilator drugs that were never designed for inhalation when there are drugs on the market that are. The $\mathrm{pH}$ of 10, it's hypotonic; I also worry about the function of the vibrating mesh with the hypotonic solution as well, to Ariel's [Berlinski] earlier point. There are multiple reasons we probably should not be nebulizing epoprostenol when we have better drugs on the market.

Kuch: I agree, I have more interest in iloprost because of its greater stability and longer half-life, which results in easier storage, and the cost is not as prohibitive. As a therapist, I like the fact that you actually get an effect for up to $2 \mathrm{~h}$. If we have a consistent method of delivery and we can give a treatment and then come back in $2 \mathrm{~h}$ and do the assessment, it's a little better workflow and potentially safer then continuous epoprostenol, where the pump could fail; there's also risk with confusion of inhalational preparations with intravenous preparations. This is a very real risk; tubing can get switched up. It's happened with feeding and intravenous lines, and it could easily happen with these medications, and it would be absolutely catastrophic.

* Branson: I am sitting on the outside of pediatrics, and I heard you say INO doesn't really help very much, so let's use a cheaper probably less safe way to do something that doesn't help very much. Maybe the real issue is the 
orders for implementation with this whole class of drugs, regardless of whether it's INO or some kind of aerosolized vasodilator. If the evidence doesn't support the use, don't use it.

Kuch: I don't think there's enough evidence to say, from an outcomes perspective, that it should be limited. I don't think we should limit access to INO because the patient population is tenuous. A child comes in, optimize their ventilation, INO-stabilize the child, and the patient does well. My perspective on this is exactly what you're saying. I think that we should look at what we do when it comes to INO and other therapies for critical illness much like we do with sepsis. It should be considered a goal-directed therapy. We could easily do this with INO. A child comes in and is now, by definition of pediatric ARDS, a can- didate for INO, and these are the steps we take. At $24 \mathrm{~h}$ after stabilization, which could be tweaking of inotropes, optimizing ventilation, getting volume status corrected, continuous renal replacement therapy; at $24 \mathrm{~h}$, reassess whether the patient has improved, and if there is no more response, then we wean the INO off. This is not evidence-based in any way, I'm just suggesting something we need to look at and build. If the child is a responder, you leave them on until a defined point, and we need to identify at which point you consult cardiology or bring someone in to say, "this is ' $\mathrm{X}$ ' and we need to go down another pathway." Instead of letting them remain on a high dollar therapy that is no longer providing clinical benefit. To do that, I think it needs to be RT-driven with good communication with the physicians. That's the direction where we become more patient care-centered and fiscally respon- sible, having both the entry criteria and an exit strategy.

\section{REFERENCES}

1. Todd Tzanetos DR, Housley JJ, Barr FE, May WL, Landers CD. Implementation of an inhaled nitric oxide protocol decreases direct cost associated with its use. Respir Care 2015;60(5):644-650.

2. Dobyns EL, Cornfield DN, Anas NG, Fortenberry JD, Tasker RC, Lynch A, et al. Multicenter randomized controlled trial of the effects of inhaled nitric oxide therapy on gas exchange in children with acute hypoxic respiratory failure. J Pediatr 1999;134(4):406412.

3. Bronicki RA, Fortenberry J, Schreiber M, Checchia PA, Anas NG. Multicenter randomized controlled trial of inhaled nitric oxide for pediatric acute respiratory distress syndrome. J Pediatr 2015;166(2):365-369.e1.

* Richard D Branson MSc RRT FAARC, Deputy Editor, RESPIRATORY CARE.

This article is approved for Continuing Respiratory Care Education credit. For information and to obtain your CRCE

(free to AARC members) visit 